\title{
SCC in PWRs: Learning from a Bottom-Up Approach
}

\author{
SERGIO LOZANO-PEREZ, JUDITH DOHR, MARTINA MEISNAR, \\ and KAREN KRUSKA
}

\begin{abstract}
Stress corrosion cracking (SCC) of steels and Ni-base alloys in the pressurized water reactor (PWR) primary circuit has been a cause for reactor outages for many decades. Although the nuclear industry has made a considerable research effort to understand and predict SCC in this system, this enterprise is complicated by the sheer number of interdependent variables that have a major influence on the degradation behavior. SCC is highly time-dependant and often only sets in after many years. Therefore, autoclave testing, even with accelerating conditions, is an expensive and time-consuming endeavor. However, the results collected by a great number of research groups over many years have identified the most important parameters and, in many cases, how they influence the degradation behavior. The community has been constantly working on the development of a general theory that encompasses the underlying mechanisms and is capable of describing and predicting the observed degradation behavior. In the last two decades, the focus of research has shifted from the traditional approach of autoclave testing (for susceptibility and crack growth rates) to high-resolution microscopy and chemical analysis. The newly available techniques are providing data on chemical and structural changes locally at the crack tip where SCC occurs. The techniques covered in this review can provide very high chemical sensitivity at atomic resolution, which is ultimately needed in the quest for a generalized theory.
\end{abstract}

DOI: $10.1007 / \mathrm{s} 40553-014-0020-\mathrm{y}$

(C) The Minerals, Metals \& Materials Society and ASM International 2014

\section{INTRODUCTION}

Currently more than 270 pressurized water reactors (PWRs) with a capacity of over $250 \mathrm{GW}$ and a yearly output of about $1680 \mathrm{TWh}$ are producing 8.3 pct of the world's electricity. ${ }^{[1]}$ With increasing operating life times, environmental degradation issues, such as stress corrosion cracking (SCC), can lead to substantial economic losses from service outages and costs for replacement components. 114 PWRs have been connected to the world's energy grid for more than 30 years, with another 87 crossing the 30 -year-mark in the next 5 years. For this reason the last decade has seen an immense research effort to understand the underlying mechanisms for SCC in steels and Ni-base alloys relevant to PWRs. This review focusses on the processes and mechanisms on the primary site and how recent high-resolution characterization approaches have contributed to improve our understanding.

Traditionally, autoclave testing over long periods of time was used to measure initiation times and crack growth rates (CGRs). Fracture surfaces were analyzed in the scanning electron microscope (SEM). Transmission electron microscopy (TEM) was occasionally used to understand the alloy microstructure but due to the

SERGIO LOZANO-PEREZ, George Kelley Senior Research Fellow, JUDITH DOHR and MARTINA MEISNAR, D.Phil. Students, and KAREN KRUSKA, Postdoctoral Research Assistant, are with the Department of Materials, University of Oxford, 16 Parks Rd, OX13PH Oxford, U.K. Contact e-mail: sergio.lozano-perez@ materials.ox.ac.uk

Manuscript submitted November 1, 2013.@

Article published online May 28, 2014 complexity of the analysis and the time required to prepare samples and analyze them, never became mainstream. In the last 15 years, with the availability of modern focussed ion beam (FIB) techniques for sitespecific sample preparation, high-resolution techniques with high chemical sensitivity such as analytical transmission electron microscopy (ATEM) and atom-probe tomography (APT) have started providing data and making their use worthwhile. These techniques can provide information about the crucial chemical and mechanical processes occurring at the crack tip. FIB 3D slicing and electron or X-ray tomography are now finally producing high-resolution $3 \mathrm{D}$ data that helps visualizing the real nature of defects and cracks. Electron backscatter diffraction (EBSD) and digital image correlation (DIC) have recently been employed to understand stress fields around cracks and their role in crack propagation. Modern autoclaves are designed to avoid self-cation pickup and facilitate ultra-short exposures to simulate the atomic processes occurring at crack tips.

Researchers have tried to quantify and predict stress corrosion susceptibly and CGRs analytically and empirically. ${ }^{[2-5]}$ Original equations have been altered and adapted for new materials and conditions. ${ }^{[6,7]}$ Some of the suggested equations, mechanisms, and models appear to describe the characteristics of SCC in certain systems accurately, although direct validation of mechanisms through high-resolution characterization is still scarce.

A large number of advanced experiments covering an extensive and impressive parameter space have been published in the literature in the last decades. Some of this data has been reviewed and summarized by Scott, ${ }^{[8]}$ 
Arioka, ${ }^{[9]}$ Staehle ${ }^{[10,11]}$ and Shoji ${ }^{[12]}$ This review discusses the mechanisms evolving in the literature and the importance of new findings through high-resolution characterization for these mechanisms. Due to the amount of data available in the literature, it has been impossible to include everything in the Section I, but this has already been covered in other reviews.

\section{MECHANISMS PROPOSED TO EXPLAIN PWSCC}

To reliably predict the susceptibility, initiation times and stress corrosion CGRs for new systems, researchers are trying to understand the underlying mechanisms that govern SCC. From the different appearances of crack surfaces, the different time scales-from hours to decades - and different electrochemical conditions it is clear that no one single mechanism can be responsible for SCC in every system. This review focusses on mechanisms and models suggested to describe SCC in the steels and $\mathrm{Ni}$ alloys and under the conditions that are relevant to PWR primary water systems. These mechanisms rely on several processes than can induce crack growth: diffusion of atoms at the crack tip into solution, shear movement of atoms at crack tips (either by emitting or attracting dislocations to the crack tip), tensile separation of atoms at the crack tip (decohesion) or, less likely, surface diffusion of atoms from the crack tip onto the crack flanks. A comprehensive review can be found in Reference 13. Next, the most relevant ones will be briefly described. They have been used over the years to explain experimental observations, mostly indirect. Although they all have some controversial aspects, their key ideas still remain current and can potentially explain some of the observed phenomena.

\section{A. The Film-Rupture Model}

The film-rupture model (FRM) is sometimes referred to as the slip-dissolution model or a combination of both of these terms. ${ }^{[14]}$ It assumes that the passivating film consisting of corrosion products on the surface of the metal is ruptured by the applied stress and unprotected metal is revealed. The newly exposed metal starts dissolving in the surrounding environment until a new passivating film has developed. This new film is ruptured again and a crack grows as the cycle repeats. The name "slip-dissolution" model accounts for the idea that film rupture can occur due to displacement along a slip band, although it can also be caused by homogeneous strain in the crack tip region.

In $1952 \operatorname{Logan}^{[15]}$ described the FRM as part of a generalized theory of stress corrosion suggested by Mears. He proposed that the corrosion is caused by an electrochemical mechanism and moves along anodic paths (such as GBs) in the more electronegative metal matrix; the corroded areas in the metal will lead to high stress concentrations in the oxide regions. If the attack is becoming deeper and the radius of the affected area decreases, the stress concentration is more localized and stresses are higher. Such highly localized stress conditions can cause the metal to tear apart; the fresh metal surfaces are even more anodic and cause an increase in current from the base of the corroded area to the unaffected surface.

The FRM is rather intuitive if a constant strain or loading rate is assumed, but it becomes more complicated if static loading and therefore a non-constant strain rate can be considered. ${ }^{[16]}$ Vermilyea $^{[17]}$ proposed that this issue can be overcome by considering dissolution at the crack tip to move the crack forward into the plastic strain field around the former crack tip, which causes plastic deformation, i.e., the crack opens and generates a new strain field ahead the new crack tip. This means that the plastic deformation does not occur during the dissolution/repassivation stage but afterward by a creep type mechanism. If this model is correct the stress corrosion cracks would grow in discrete steps. In 1982 Ford published a detailed diagram showing that the CGR is proportional to the anodic current density which supports the FRM. ${ }^{[18]}$ In 1988 Andresen and Ford further reported that the FRM has been statistically validated for type 304 and 316 stainless steels, at least for the metallurgical and environmental conditions characteristic of light-water reactors. ${ }^{[19]}$ Nevertheless, the model has been criticized because the predicted anodic dissolution rates are not sufficiently high to account for the observed rates of crack propagation in some systems, including brass and austenitic stainless steels. ${ }^{[20]}$ In the last two decades, various papers have been published trying to either simplify the model or introduce additional parameters. ${ }^{[21,22]}$ It was also shown that, for the Vermilyea model, relatively large depths of corrosion are necessary in every film rupture cycle to obtain realistic plastic strain distributions ahead of the crack tip. ${ }^{[23]}$ These depths would also lead to much wider crack openings and more heavily corroded fracture surfaces, than experimentally observed. It was therefore concluded that the FRM model is not applicable for transgranular SCC and the FRM became primarily associated with intergranular SCC (IGSCC). ${ }^{[2]}$ Newman and Healey describe the FRM as a "relatively mature and successful attempt to rationalize the kinetics of SCC" but they also pointed out that it does not apply to all systems. ${ }^{[16]}$

Recently, Hall has published a few short papers evaluating the Shoji ${ }^{[6]}$ and Ford-Andresen ${ }^{[25]}$ models. $\mathrm{He}$ has also proposed his own model with a variable stress intensity factor. ${ }^{[7]}$ Hall's ideas were used by Vankeerberghen et al. ${ }^{[26]}$ as a basis to model the propagation rates for $316 \mathrm{SS}$ in PWR conditions. The authors concluded that, although their results are consistent with the published experimental data, they neither prove nor disprove the validity of the FRM mechanism. However, they still consider the model plausible and applicable to engineering calculations.

For a validation of this model, the following experimental observations are expected:

- Bare metal exposed at the crack tip if the crack final growth step happened prior to sample extraction for characterization or some oxide ahead of the crack tip if there was enough time for the oxide to form prior to sample extraction. 
- A series of slips on the crack flanks associated with the crack advance and its cyclic nature. Fracture surfaces would have a step-like appearance.

\section{B. H-Related Mechanisms}

$\mathrm{H}$ has been known to severely embrittle steel and other metals. ${ }^{[27]} \mathrm{H}$ embrittlement (HE) can either be caused by gaseous $\mathrm{H}\left(\mathrm{H}_{2}\right)$, or in solution from $\left(\mathrm{H}_{3} \mathrm{O}\right)^{+}$ or $\mathrm{H}_{2} \mathrm{O},{ }^{[28]}$ but it is important to note that the effects of delayed failure and HE have to be carefully distinguished from SCC. According to Shreir, SCC is anodic dissolution moving along a favored path. Therefore SCC can only occur if the corrosion process is not stopped by a negative potential within the metal (cathodic protection). This negative potential, however, is exactly what causes $\mathrm{H}$ charging and leads to HE. ${ }^{[28]}$ SCC can easily include $\mathrm{H}$-assisted cracking (HAC). Lynch $^{[29]}$ pointed out that the similarities in appearance of HAC and SCC indicate that both processes might occur by a common mechanism. The most popular mechanisms involving $\mathrm{H}$ are:

- Adsorption induced slip mechanism: In ductile materials stress-activated dislocation sources produce large strain fields ahead of the crack tip that can create voids ahead of the crack tip, which on joining up cause the crack to advance. In brittle materials higher stresses are necessary for extensive dislocation mobility to occur. Lynch suggests that $\mathrm{H}$ atoms are adsorbed to the crack surfaces near the crack tip after dissociation of $\mathrm{H}$ molecules, $\mathrm{H}$-sulfide, or water molecules, or after electrochemical reactions in an external environment. These adsorbed $\mathrm{H}$ atoms weaken inter-atomic bonds and give rise to higher dislocation activity in the crack tip region. Strain fields are formed ahead of the crack due to dislocations nucleating at the crack tip, which will again lead to the growths of microvoids. The coalescence of these voids with the crack tip by an alternate slip mechanism will result in macroscopic crack growth of cleavage-like appearance. ${ }^{[29]}$

- The Troiano-Oriani decohesion hypothesis and variations: This model proposes that the cohesive force between atoms decreases linearly with a rising $\mathrm{H}$ concentration. ${ }^{[27,30]}$ If $\mathrm{H}$ concentrates in the regions of tensile stress ahead of the crack tip in sufficient quantity the weakened bonds between the metal atoms lead to an increase in crack growth. $\mathrm{H}$ then diffuses to the new position of the crack front and the process is repeated. Although decohesion hypothesis was a promising approach, it could not be applied to material systems without voids experimentally observed ahead of the crack tip; this includes austenitic stainless steels at low temperature. Therefore, Magnin et al. ${ }^{[31]}$ developed a model fitted to ductile fcc single phase materials, such as austenitic stainless steels.

- H-enhanced local plasticity (HELP): A mechanism first suggested by Beachem and based on detailed analysis of fracture surfaces of four different ferritic steels. ${ }^{[32]}$ The mechanism was formulated based on four interactions between $\mathrm{H}$ and steel, although it could be extended to other metals, including Ni-based alloys:

1. Evolving $\mathrm{H}$ enters the metal matrix at growing crack tips.

2. Molecular $\mathrm{H}$ dissociates at clean deforming surfaces and subsequently diffuses into the metal matrix. ${ }^{[33]}$

3 . $\mathrm{H}$ migrates to regions of higher triaxial tensile stresses. $^{[34]}$

4. Dissolved $\mathrm{H}$ aides the deformation of the ferrite matrix (in mild steels). ${ }^{[35]}$

Beachem suggests that $\mathrm{H}$ diffuses into the lattice ahead of the crack tip and aids whichever type of deformation the matrix will allow. The stress intensity factor and the $\mathrm{H}$ concentration in solution at the crack tip will determine if micro-void coalescence (MVC), quasi cleavage (QC) or intergranular (IG) fracture occurred. ${ }^{[32]}$ This mechanism was in later years mostly promoted by Birnbaum and co-workers at Illinois University. ${ }^{[36,37]}$ In a recent work, ${ }^{[38]}$ a high-resolution study of fracture surfaces of steels tested under $\mathrm{H}$ gas pressure is presented. TEM cross sections revealed an extremely high dislocation density in the entire sample. As the sample history is not thoroughly described in the publication and no uncharged material was examined, it remains unclear to what extent the dislocations are caused by $\mathrm{H}$. Apparently, a reduction in fracture toughness was observed compared to $\mathrm{H}$ poorer conditions. It is argued, that the continuous dislocation density and the microscopically rough fracture surfaces rule out a decohesive mechanism. However, the presented micrographs show a dark layer about $50 \sim \mathrm{nm}$ wide near the fracture surface, which is not mentioned in the paper and could relate to a higher dislocation density region.

For a validation of this model, the following experimental observations are expected:

- Enough H trapped in the crack tip vicinity, with a concentration depending on local stresses and chemistry.

- A local change in mechanical properties or diffusion rates.

- A correlation between CGR and $\mathrm{H}$ availability at the crack tip.

- A series of voids ahead of the crack tip.

\section{Internal Oxidation}

In 1993 Scott and Le Calvar suggested a diffusioncontrolled internal oxidation mechanism for Ni-based alloys similar to those traditionally associated with hightemperature corrosion. ${ }^{[3]}$ Internal oxidation means that less noble alloying elements are oxidized, while the balance (in the discussed case the $\mathrm{Ni}$ ) remains metallic. Scott and Le Calvar argue that such a mechanism is particularly important for Ni-based alloys in atmospheres 
with low partial pressures of $\mathrm{O}$ as the $\mathrm{Ni} / \mathrm{NiO}$ equilibrium is at a higher potential then the respective equilibria of typical alloying elements. They suggest that grain boundary (GB) embrittlement could be controlled by gas bubble formation $\left(\mathrm{CO} / \mathrm{CO}_{2}\right)$, internal oxide formation, or formation of a layer of $\mathrm{O}$ atoms at the GBs. Rebak and Szklarska-Smialowska criticize that in the equation provided for the first case the CGR is proportional to the stress intensity factor at the crack tip and the predicted CGR are too high. ${ }^{[39]}$ Later, Scott and Le Calvar assumed $\mathrm{O}$ diffusion rates which are not stress dependent and consequently obtain stress-independent CGRs. The CGRs predicted, if it is assumed that $\mathrm{O}$ diffuses into the GB without oxidizing all the $\mathrm{Cr}$ along the GB, are in reasonable agreement with experimentally observed CGRs in Alloy $600{ }^{[3]}$ Fine IG oxides at the crack path and ahead of the crack tip have been reported after high-resolution TEM characterization, supporting the internal oxidation mechanism. ${ }^{[40,41]}$ Recent atom-probe data also supports the existence of a dispersion of discrete oxide particles ahead of the oxidation front (see Section IV-G in this review). Due to the fact that the major component of an alloy needs to be nobler than the main alloying elements to allow for internal oxidation in the classical sense, this mechanism was almost exclusively associated with Alloy 600, although its predictions have been validated in stainless steels. In both types of alloys, a Ni-rich area is always found at the oxide-metal interface. Along grain boundaries or fast-diffusion features (dislocations, deformation bands), the Ni-rich region can extend for hundreds of nanometers.

As it has been shown through this section, although a number of elaborate models have been suggested, there is still no unified solution. Many of us believe that it is very possible that there is no single mechanism for SCC, but that one or the other might be more appropriate in a given situation, or that in fact a combination of the mechanisms applies. ${ }^{[14,42]}$

For a validation of this model, the following experimental observations are expected:

- Presence of oxidation ahead of the crack tip.

- A brittle oxide.

- An oxide growth rate (ahead of the crack tip) faster/ comparable to the CGR.

\section{III. “TRADITIONAL” CHARACTERIZATION AND TESTING OF SCC}

SCC is highly time dependent and a result of highly localized electrochemical processes at the crack tip. These processes are affected by temperature, electrochemical potential, local chemistry, local microstructure, and any applied stresses. As a result, prediction is challenging, as it needs to address the individual or synergistic effect of all these variables. Data based on previous experiences or failures, as well as laboratory tests, have been gathered over the years, forming the basis to our attempts to predict SCC behavior. Samples from service components may carry a complex history making data interpretation more difficult. These uncertainties can be eliminated in laboratory tests under controlled environments. In many cases, the environment of interest will only produce SCC after years of operation. Therefore SCC tests are often accelerated by introducing a more aggressive environment: changing potentials, temperatures, adding impurities, increasing the applied stress, or pre-deforming the material. ${ }^{[43]}$ This is a necessary compromise since data is expected to forecast future cracking behavior before it occurs in service. However, it should be acknowledged that the active mechanisms in accelerated tests might not be identical to those in in-service components.

Depending on the testing conditions that are to be simulated, pre-cracked or smooth (i.e., non-pre-cracked) specimens can be used for the SCC test. A smooth sample represents an initially flawless material, although different levels of surface finish can be used, whereas a precracked specimen simulates already existing cracks or flaws in the material. ${ }^{[44]}$ Smooth surfaces are used to study crack initiation or the initial stages of GB oxidation. This approach facilitates characterization through the use of an "artificially" simplified microstructure (potentially defect-free) although it might not realistically reproduce in-service behavior. ${ }^{[45]}$ Pre-cracked specimens, where a crack has been developed from a machined notch by fatigue, are often subjected to either to a constant load/displacement or to an increasing load/displacement during exposure to a simulated environment. The objectives of these tests are to investigate the conditions under which a stress corrosion crack propagates and at which rate as well as the threshold stress intensity factor for Mode I opening, $K_{\mathrm{I}} \mathrm{sCC}$, at which SCC begins to develop.

To date most of our predictive capabilities are based on results from crack initiation or growth rate tests. These tests were performed in different laboratories, not always under identical conditions, compromising their comparability. However, experiments planned carefully, where only one variable was changed at a time, have allowed studying the effect of key parameters. For this review, we will concentrate on stainless steels (mostly 304 and 316) and Ni alloys (mostly 600 and 690), all of them very relevant for PWRs.

\section{A. Key Findings/Observations}

\section{Effect of cold-work}

During cold-working or work-hardening dislocations, stacking faults, localized slip planes, or deformation bands are created in the material through plastic deformation. All these defects prevent new dislocations from nucleating and cause the material to harden. Microstructures typical of in-service components can be simulated by laboratory cold-working with some degree of reproducibility. There are several ways to systematically cold-work (CW) a material; however, samples tested under simulated PWR primary water conditions are usually cold-rolled to a reduction in thickness. Coldrolling to e.g., a 20 pct reduction in thickness will be referred to 20 pct $\mathrm{CW}$ in this review.

Although it is well-known that $\mathrm{CW}$ modifies the mechanical properties of materials and many investigations 
have been published, its exact impact on crack growth and SCC resistance is only beginning to be established. ${ }^{[41,46-48]}$

In the 1980s, CW was found to be beneficial for longterm corrosion resistance in type 304 stainless steels. ${ }^{[49,50]}$ Langevoort established that $\mathrm{CW}$ does not alter the oxidation mechanisms or oxide compositions but affects the diffusion rates through the oxide and the metal, modifying the oxidation rates. This effect may be due to the development of an increasing proportion of high-angle sub-boundaries that act as additional fastdiffusion paths. ${ }^{[41,51,52]}$ In support of this theory, Arioka et al. ${ }^{[53]}$ found connections between the SCC growth rate and creep by GB diffusion which depends on temperature, $\mathrm{CW}$, and the rolling direction. It was also found that cold-working slightly increases surface oxide thicknesses under PWR primary water conditions. It appears that the higher oxidation rate due to $\mathrm{CW}$ results in an increase of the thickness of the protective $\mathrm{Cr}$-rich oxide layer at the surface of stainless steels. However, these studies, which relied on depth profiling for measuring surface oxides depths, lacked the spatial resolution to identify localized oxidation along grain boundaries and deformation bands. As it was later demonstrated, CW can drastically accelerate localized oxidation. ${ }^{[54]}$

For stainless steels under PWR conditions, an increase in the CGR with increasing $\mathrm{CW}$ level has been observed and reported in various publications. ${ }^{[55-57]} \mathrm{No}$ differences between 304 and 316 stainless steels were observed. ${ }^{58]}$ More importantly, there seems to be a minimum amount of $\mathrm{CW}$ required for $\mathrm{SCC}$ to be reproduced in stainless steels under simulated PWR conditions, which seems to be around 5 pct. ${ }^{[59,60]}$ Higher CW levels will produce higher CGRs. This increase in the CGRs has been attributed to hardening of the material, increased local oxidation, higher density of defects, and creation of residual stresses. ${ }^{[41]}$

Recent work by Arioka et al. focused on the requirements for the transition from incubation to steady SCC growth in type SUS316 stainless steel. The experiments showed that slight deformation at the tip of a $50 \mu \mathrm{m}$ pre-crack causes local stress to develop. When the local stress attained a certain critical stress, SCC growth from the pre-crack tip to grain boundaries began. ${ }^{[61]}$ This work suggests that the formation of cavities at the final stages of the initiation period could be the first indicator for stress corrosion crack propagation. The formation of cavities could be enhanced with $\mathrm{CW}$ or elevating temperature and potentially weakens the GB bonding strength, leading to SCC growth. These interdependencies are established and discussed in more detail in previous publications. ${ }^{[62-64]}$

In Ni-base alloys, CW also has a detrimental effect, although unlike in stainless steels, it is not a necessary pre-requisite to observe SCC crack growth. ${ }^{[65]}$ It should be noted that Alloy 690 CGRs under PWR primary conditions are remarkably lower than those of Alloy 600 and CW is necessary if SCC is to be observed in lab tests. In some cases, it remains immune to $\mathrm{SCC}$ until 20 pct $\mathrm{CW}$ levels ${ }^{[66]}$ or shows a better performance at higher values of deformation. ${ }^{[67,68]}$ Similarly good performance was observed with initiation tests, where Alloy
690 remained free from cracking, even with high levels of CW. ${ }^{[69]}$ In some cases cracks were observed after the autoclave testing, but only in deformed samples, suggesting that $\mathrm{CW}$ in Ni-base alloys seems to play a more important role for crack initiation. ${ }^{[55]}$ Furthermore, cold-worked Ni-base alloys are more affected by SCC under low potential conditions. ${ }^{[70,71]}$

\section{Effect of alloy composition}

In order to shed some light on the influence of the $\mathrm{Cr}$ concentration on oxide formation and SCC CGRs, Lozano-Perez et al. ${ }^{[41]}$ investigated the difference between 304-type stainless steel samples with different levels of $\mathrm{Cr}$. The results showed that the lower the $\mathrm{Cr}$ content in the alloy, the higher the CGR and the more extended the observed $\mathrm{Cr}$-rich oxide ahead of the crack tip. It was suggested that the lower $\mathrm{Cr}$ availability in the lower-Cr-alloys might delay the formation of a protective $\mathrm{Cr}$ oxide layer and allow more extensive corrosion attack. The $\mathrm{Cr}$ content also influences the type of oxides that form during exposure. Oxide films on alloys with higher $\mathrm{Cr}$ contents are thinner and richer in $\mathrm{Cr}, \mathrm{Cr}_{2} \mathrm{O}_{3}$ is frequently observed. The oxides have better mechanical properties and higher passivation rates. ${ }^{[72,73]}$

The effect of Ni on SCC susceptibility has also been studied. ${ }^{[74]}$ While the $\mathrm{Ni}$ content in the investigated range had little impact, a higher $\mathrm{Cr}$ content clearly improved SCC resistance. These observations support the observed better resistance of Alloy 690 (with over 30 pet $\mathrm{Cr}$ ) to SCC as compared to Alloy $600 .^{[72,75,76]}$

\section{Effect of $G B$ microstructure}

The microstructure of the alloy plays an important role to SCC susceptibility. Since most of the observed cracking is IG, the structure and chemistry of GBs are of special interest. Since the introduction of the idea of "GB design and control" in 1984 by Watanabe, ${ }^{[77]}$ the influence of GB properties to SCC has been a much studied subject. GBs play a crucial role in a material's deformation and fracture behavior. IG phenomena like GB sliding, migration, segregation, precipitation, and fracture are linked to increased plasticity, especially at elevated temperatures. In addition, GB carbides and GB structure can directly affect the chemical composition and mechanical behavior of GBs.

Several studies have revealed that an increased number of coincident site lattice (CSL) boundaries in the alloy structure has a positive effect on SCC resistance. ${ }^{[78,79]}$ In Alloy 600, CSLBs were always more resistant to cracking than high-angle boundaries (HABs), regardless of the microstructure or testing conditions. The most resistant microstructure is assumed to contain a high fraction of CSL boundaries, mixed with HABs. Coherent twins $\left(\sum 3 s\right)$ are the only type of CSL boundaries that systematically show a harder resistance to cracking. Their beneficial influence relies on their role as barriers for crack propagation.

The role of slip transfer is recently getting more attention. Alexandreanu and Was, ${ }^{[80]}$ as well as West (for Irradiation-Assisted SCC), ${ }^{[81]}$ have shown that cracking is favored when neighboring grains are in such orientation that slip transfer is not favorable and 
deformation in the form of high dislocation density occurs around the GBs. This is in good agreement with work by Gertsman and Bruemmer. ${ }^{[82]}$

\section{Effect of carbon}

Nuclear grade steels and Ni-base alloys usually have low $\mathrm{C}$ contents (up to $0.15 \mathrm{wt} \mathrm{pct}$ ). $\mathrm{C}$ mainly influences the microstructure by forming inter- and/or intragranular $\mathrm{Cr}$-based carbide precipitates $\left(\mathrm{Cr}_{23} \mathrm{C}_{6}\right.$ and $\left.\mathrm{Cr}_{7} \mathrm{C}_{3}\right){ }^{\left[{ }^{[83]}\right.}$ The $\mathrm{C}$ content is, together with heat treatment temperature and duration, one of the main manufacturing parameters determining the microstructure and hence also the cracking resistance of the alloy in complex ways. Diverse studies have shown that a continuous network of IG carbides results in an improved SCC resistance of the alloy. ${ }^{[46,79,84-87]}$ Intragranular carbides have not been shown to have a beneficial effect. ${ }^{[88]}$ The influence of special GBs (e.g., CSL boundaries, low, and HABs) together with $\mathrm{C}$ in solution and GB carbides was also investigated. ${ }^{[79]} \mathrm{It}$ was found that higher $\mathrm{C}$ content in solution increases IGSCC resistance and $\mathrm{GB}$ carbides further improve resistance to SCC on top of already present benefits. The implication is that carbides might not only inhibit crack initiation and therefore decrease SCC susceptibility, but also slow down crack propagation. Bruemmer et al. ${ }^{[89]}$ suggested that carbides can be a source of dislocations and attributed a stress-relieving role to IG carbides, causing the blunting of crack tips, resulting in an overall decrease of CGRs and IGSCC susceptibility.

After controlled periods of annealing the alloy becomes sensitized, i.e., IG carbide formation leads to Cr-depleted areas in the proximity of the GB. The depletion is controlled by the thermodynamics of the carbide formation together with $\mathrm{Cr}$ and $\mathrm{C}$ diffusivities in the particular alloy at the chosen temperature. ${ }^{[78]}$ Depleted zones form in a temperature range where precipitates are thermodynamically stable and the $\mathrm{Cr}$ diffusivity is high enough for carbide nucleation. The high $\mathrm{Cr}$ diffusivity allows not only sensitization of the alloy but also desensitization: at temperatures greater than $923 \mathrm{~K}\left(650{ }^{\circ} \mathrm{C}\right)$ the alloy can be healed. This means, the solute $\mathrm{Cr}$ is redistributed to compensate for the depletion around the carbides.

The role of carbides and the Cr-depleted zone is still subject of much discussion. Kai et al. ${ }^{[90]}$ reported that the amount of the Cr-depletion plays a role but the width and shape seem to be of no crucial significance. Although it is difficult to isolate the effect of $\mathrm{Cr}$ depletion, it appears that it is not an essential factor in the IGSCC of Alloy 600 in deaerated water. ${ }^{[78]}$ The general belief is that the effects of $\mathrm{Cr}$-depletion on IGSCC of Alloy 600 are minor compared to the positive effect of IG carbides. ${ }^{[46]}$ Recent work by Dugdale indicates that the beneficial role of carbides in IGSCC could be related to the fact that they deviate the crack from propagating straight down the GB. ${ }^{[1]}$

\section{Effect of water chemistry and temperature}

PWR operating temperatures range between $559 \mathrm{~K}$ and $595 \mathrm{~K}\left(286{ }^{\circ} \mathrm{C}\right.$ and $\left.322{ }^{\circ} \mathrm{C}\right)$, except for the primary circuit pressurizers which operate at $616 \mathrm{~K}\left(343^{\circ} \mathrm{C}\right) .{ }^{[92]}$
Primary water is pure water $\left(\left[\mathrm{O}_{2}\right]<10 \mathrm{ppb}\right)$ with fractions of $\mathrm{B}, \mathrm{Li}$, and $\mathrm{H}$. $\mathrm{H}$ (usually $30 \mathrm{~cm}^{3} / \mathrm{kg}$, is added to the primary side water to balance out coolant radiolysis. By maintaining a minimum concentration of dissolved $\mathrm{O}$, primary circuit material corrosion is minimized, and low redox potentials, just below the $\mathrm{Ni} / \mathrm{NiO}$ equilibrium, are maintained in the primary loop. Boric acid $\left(\mathrm{H}_{3} \mathrm{BO}_{3}\right)$ is added for neutron absorption and lithium hydroxide $(\mathrm{LiOH})$ stabilizes the $\mathrm{pH}$ of the coolant.

It was found that minor changes in the water chemistry did not affect the structure of the doublelayered oxide film but its thickness. The film thickness appeared to increase (up to a point) with increasing dissolved $\mathrm{H}$ and decreasing boric acid. ${ }^{[93,94]}$ As it will be shown in the next section, limited lateral resolution on their surface analysis prevented the observation of localized oxidation along grain boundaries or deformation bands which could be orders of magnitude deeper than the surface average.

For PWSCC of $\mathrm{Ni}$ alloys, the most influential variables are temperature and corrosion potential. Andresen et al. ${ }^{[95]}$ performed a very comprehensive study on the effects of water chemistry (corrosion potential and presence of impurities) on CGRs of Ni-based alloys. They found that small changes in $\mathrm{pH}$ or changes from pure deaerated to $\mathrm{B} / \mathrm{Li}$ deaerated water have little effect on CGRs. However, the addition of $\mathrm{O}_{2}$ to PWR primary water has a much more detrimental effect than any buffering effect of $\mathrm{B} / \mathrm{Li}$ or ammonia additions. Other studies ${ }^{[96-99]}$ have also reported that the $\mathrm{H}$ content in high temperature water or $\mathrm{H}$ gas in steam $\left[673 \mathrm{~K}\left(400{ }^{\circ} \mathrm{C}\right)\right]$ plays an important role in $\mathrm{SCC}$ behavior of Ni alloys. Morton et al., ${ }^{[96]}$ found that the maximum $\mathrm{CGR}$ rate with respect to coolant $\mathrm{H}$ variation is observed around $( \pm 80 \mathrm{mV})$ the $\mathrm{Ni}$ to $\mathrm{Ni}$ oxide $(\mathrm{Ni} /$ $\mathrm{NiO})$ equilibrium potential. ${ }^{[96,100]}$

Bruemmer and $\mathrm{Was}^{[78]}$ reported that primary water SCC has not been observed at temperatures below $523 \mathrm{~K}\left(250{ }^{\circ} \mathrm{C}\right)$; it is most significant in the hottest part of the system, where the temperature exceeds $573 \mathrm{~K}$ $\left(300{ }^{\circ} \mathrm{C}\right)$. This agrees with Hoang et al., ${ }^{[8]}$ who believe that temperature is the most influential variable to PWSCC growth rate of Alloy 600. Many experimental test results indicate that IGSCC is a thermally activated process and that the CGR is strongly dependent on temperature. Activation energy values in the literature are usually divided into the activation energies for initiation and propagation. Average values of $180 \mathrm{~kJ} / \mathrm{mol}$ for crack initiation and $130 \mathrm{~kJ} / \mathrm{mol}$ have been reported for Alloy $600^{[101]}$ and $\sim 100 \mathrm{~kJ} / \mathrm{mol}$ for crack propagation of 304 and 316 stainless steels. ${ }^{[60]}$

\section{HIGH-RESOLUTION CHARACTERIZATION OF SCC}

Until the early 1990s high-resolution characterization techniques played little or no role in SCC research. Traditionally, SCC has been investigated with surface or indirect methods because the region of interest was not accessible to techniques such as TEM or APT (or these 
techniques simply did not exist). Fortunately, the perseverance of some research groups with ion beam thinning ${ }^{[102-104]}$ and, particularly, the arrival of focus ion beams, ${ }^{[105,106]}$ finally permitted the preparation of samples suitable for the above mentioned techniques. Other techniques that will be discussed in this section and that have contributed to improve our understanding of SCC are FIB 3D slicing, X-ray and electron tomography, DIC strain mapping, NanoSIMS, and micromechanical testing.

\section{A. Transmission Electron Microscopy}

TEM is a characterization technique which covers the microns to Angstroms scale. In addition to the highresolution imaging and electron diffraction capabilities of state of the art TEMs, the multiple signals that are generated by the interaction of the electron beam with the sample, when equipped with suitable detectors, can be used to provide another broad spectrum of chemical characterization techniques, like energy dispersive X-ray spectrometry (EDX) or electron-energy loss spectroscopy (EELS) ${ }^{[107]}$

Nisbet et al. ${ }^{[108]}$ were the first to report a TEM-based study of SCC in Stainless Steels in 1993. Following their lead, other research groups gradually applied this highresolution method for studying the microstructure of their SCC specimens. Quickly the community identified high-resolution TEM studies, particularly of the inner oxide layer, as a promising tool to study SCC mechanisms and crack initiation. The observation of surface oxides and crack tips by TEM has become a common, routinely performed approach. ${ }^{[40,47,52,106,109]}$ Diffraction in the TEM can be used to study the microstructure and crystallographic orientation of selected features. Oxide films can be identified by diffraction, as shown in Figure 1. 3D reconstructions of crack tips with $\mathrm{nm}$ resolution were demonstrated by Lozano-Perez et al.$^{[110]}$ and proved very useful to visualize the exact orientations of GB planes and crystallographic defects at the crack tip region such as deformation bands or dislocations.

Analytical characterization is achieved by using EDX, EELS, or Energy-Filtered TEM (EFTEM). This approach has proven very useful to characterize grain boundaries, ${ }^{[82,111]}$ surface oxides, ${ }^{[93,112]}$ or crack tips. ${ }^{[4,52,57,103,112-114]}$ An example of high-resolution analytical characterization of crack tips can be seen in Figure 8.

\section{B. Atom-Probe Tomography}

3D APT is capable of reconstructing small portions of needle-shaped samples on an atom-by-atom basis. Ions are field-evaporated from the apex of the needle and identified using a time-of-flight mass spectrometer. Their original position in the sample is recorded by a positionsensitive detector. ${ }^{[115]}$

The necessity to directly analyze specific localized as opposed to the mainly indirect methods used in the past, was the driving force behind the use of APT or TEM that we frequently see nowadays. $3 \mathrm{D}$ atom probe is a

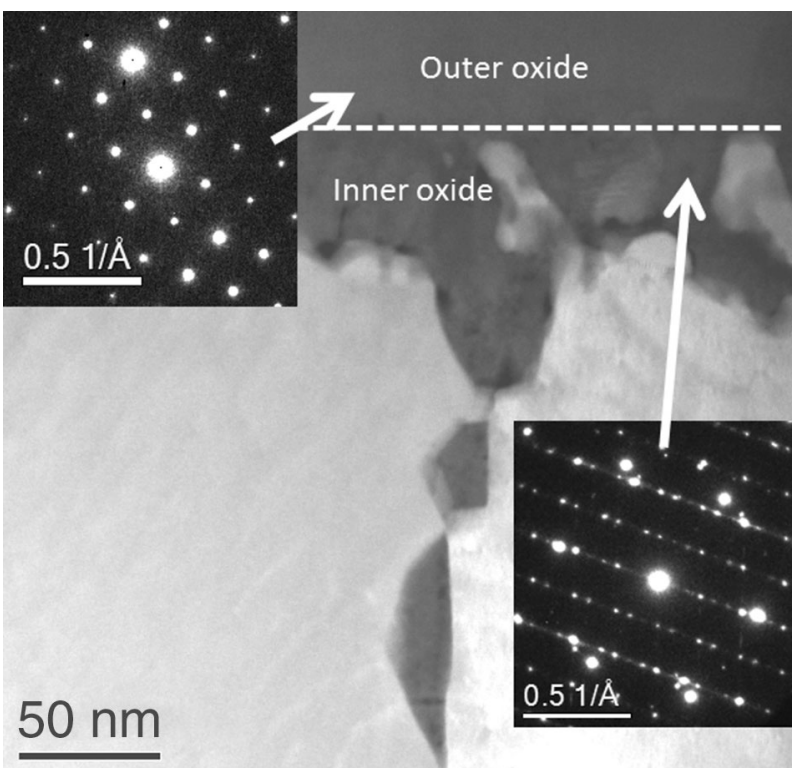

Fig. 1-HAADF image showing the surface oxides on an Alloy 600 sample (cross-sectional view) exposed to simulated PWR primary water for $1500 \mathrm{~h}$. SADP from the inner oxide layer confirmed that it is a $\mathrm{Fe}-\mathrm{Cr}$ spinel which grew in epitaxial relationship with the matrix (see brighter spots) along a $\langle 110\rangle$ orientation. SADP from the outer oxide layer confirmed that it is an Fe-Ni-rich spinel in epitaxial relationship with the matrix below, also along a $\langle 110\rangle$ orientation.

high-resolution technique with excellent chemical sensitivity and a resolution recently demonstrated to reach the picometer-level both in-depth and laterally. ${ }^{[16]}$ With the rise of new sample preparation techniques, enabling the site-specific preparation of atom probe needles, the use of atom probe for SCC characterization has become a reasonable endeavor. ${ }^{[17-123]}$ APT has allowed the study of surface oxides (Figure 2), oxidized/unoxidized grain boundaries and crack tip regions with unprecedented detail.

\section{SIMS}

Secondary ion mass spectroscopy (SIMS) is a surface analysis technique in which a primary ion beam is used to sputter material from the surface in a controlled way so it can be analyzed by a mass spectrometer. Only with the development of the NanoSIMS ${ }^{\mathrm{TM}}$, ${ }^{[24]}$ lateral resolutions of less than $100 \mathrm{~nm}$ can be achieved routinely when mapping while keeping a high mass resolution. The technique has been recently applied to the characterization of stress corrosion cracks in 304SS from PWRs with excellent results. Its high sensitivity allowed the observation of oxidation asymmetry (higher oxidation on one of the grains) and the detection of $\mathrm{B}$ segregated to grain boundaries, as revealed in Figure 3. ${ }^{[125-127]}$

\section{3D Tomography}

Several techniques are now capable of providing nmresolution data in $3 \mathrm{D}$ on key regions associated with SCC. X-ray and electron tomography were discussed in 


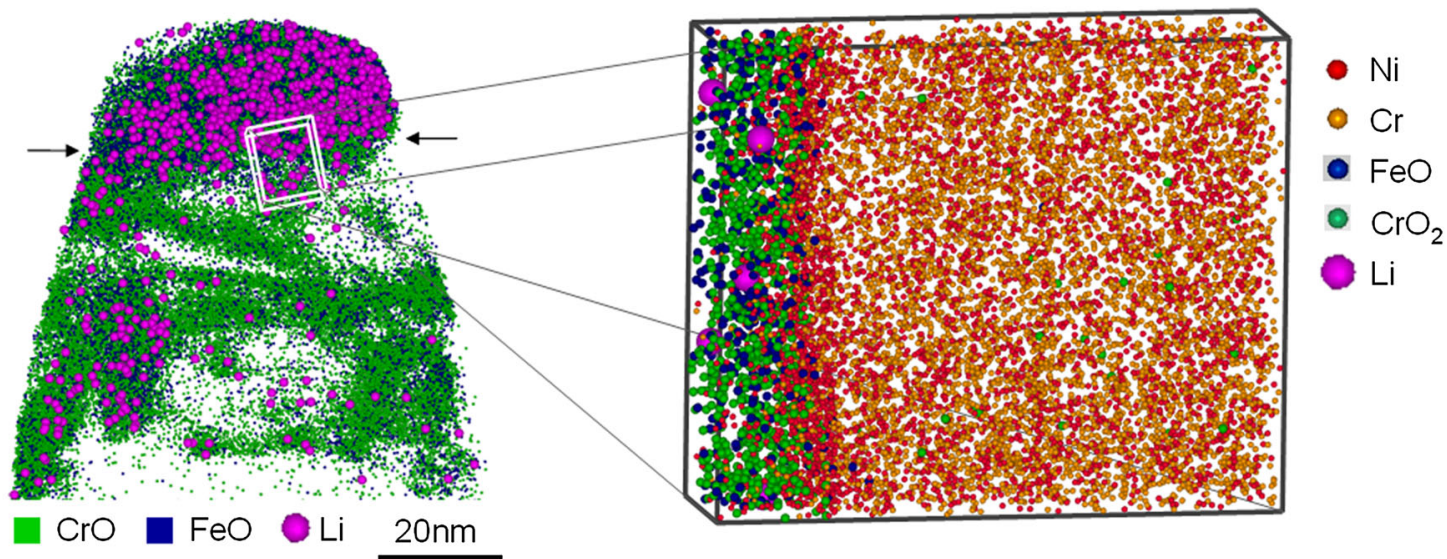

(a)

(c)

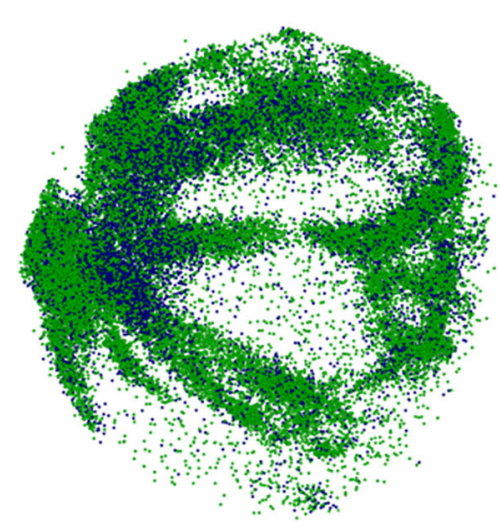

(b)

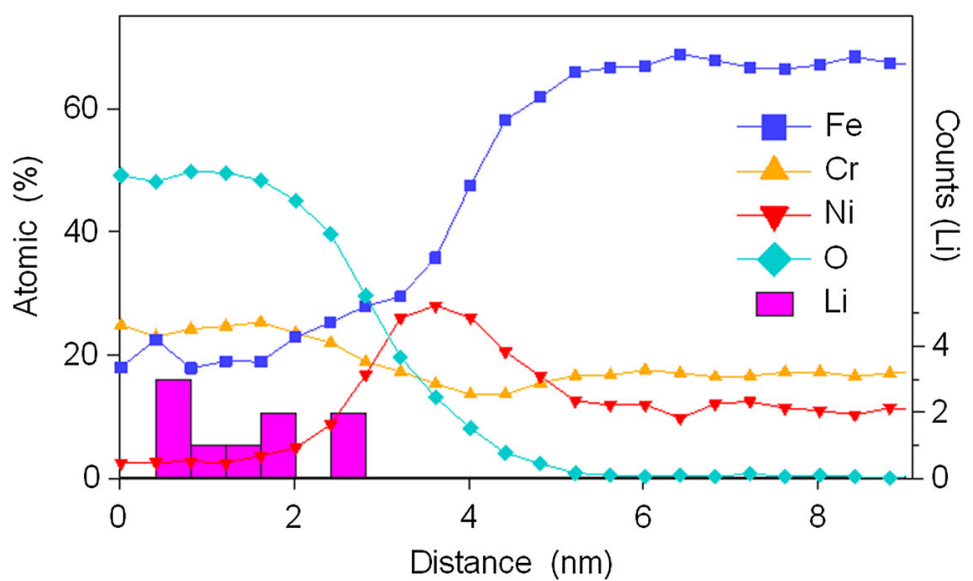

(d)

Fig. 2-(a) APT reconstruction showing the presence of lithium atoms within the cap and sub-interface oxides. The arrows indicate the location of the cap-oxide-to-metal interface. The Li atom distribution is superimposed on the oxide atom maps. (b) Top-view of the sub-interface region showing the distribution of oxides (cap oxide removed). The oxide regions beneath the cap are interconnected. (c) Sub-volume $(5 \times 15 \times 18 \mathrm{~nm}$; $\sim 40,000$ detected atoms) taken from the cap-oxide-to-metal interface showing selected species. (d) Concentration profile across the oxide-metal interface generated using the proxigram technique. The presence of lithium is represented by an atom-count because its concentration is very low. Uncertainties in the data points are comparable to the marker size. Reprinted from Ref. [148], with permission from Elsevier.

References 128 to 131 and were useful to visualize the crack path in $3 \mathrm{D}$ as well as any regions of less susceptibility. However, FIB 3D slicing was found to be the technique that can quickly and efficiently provide the most relevant 3D data. Capable of achieving $\mathrm{nm}$-resolution covering volumes of thousands of $\mu \mathrm{m}^{3}$, it has been successfully applied to the reconstruction of cracks and oxide layers on coupon specimens oxidized under PWR conditions. ${ }^{[54]}$ As illustrated in Figure 4, the higher susceptibility of grain boundaries was easily observed and new, more realistic, oxidation rates and their dependence on stress, and CW were measured.

\section{E. Micromechanical Testing}

Macroscopic behavior of materials is often controlled by microscopic events, which has driven interest in testing and analyzing increasingly smaller features. The ability to perform mechanical tests on the micron-scale, with modeling and high-resolution chemical and structural analysis on the same scale, now makes it possible to understand some of the mechanisms controlling one of the most complex modes of fracture: SCC. The instrumentation required for such approach has not been available until very recently and the first results have started appearing in the literature. ${ }^{[91,132]}$ It was shown that, through a multifaceted approach, individual grain boundaries oxidized during exposure to simulated pressurized nuclear reactor cooling water, can be mechanically tested and their resistance to fracture can be quantified. These results can have direct consequences in understanding the mechanisms controlling SCC propagation and initiation. In Figure 5, an example of an IG crack induced on the oxidized portion of a GB is shown. The crack path was fully reproduced by finite element modeling, which allowed an estimation of the oxidized GB strength. The values found are compatible with the stresses required to activate $\mathrm{SCC}$ in these alloys. 

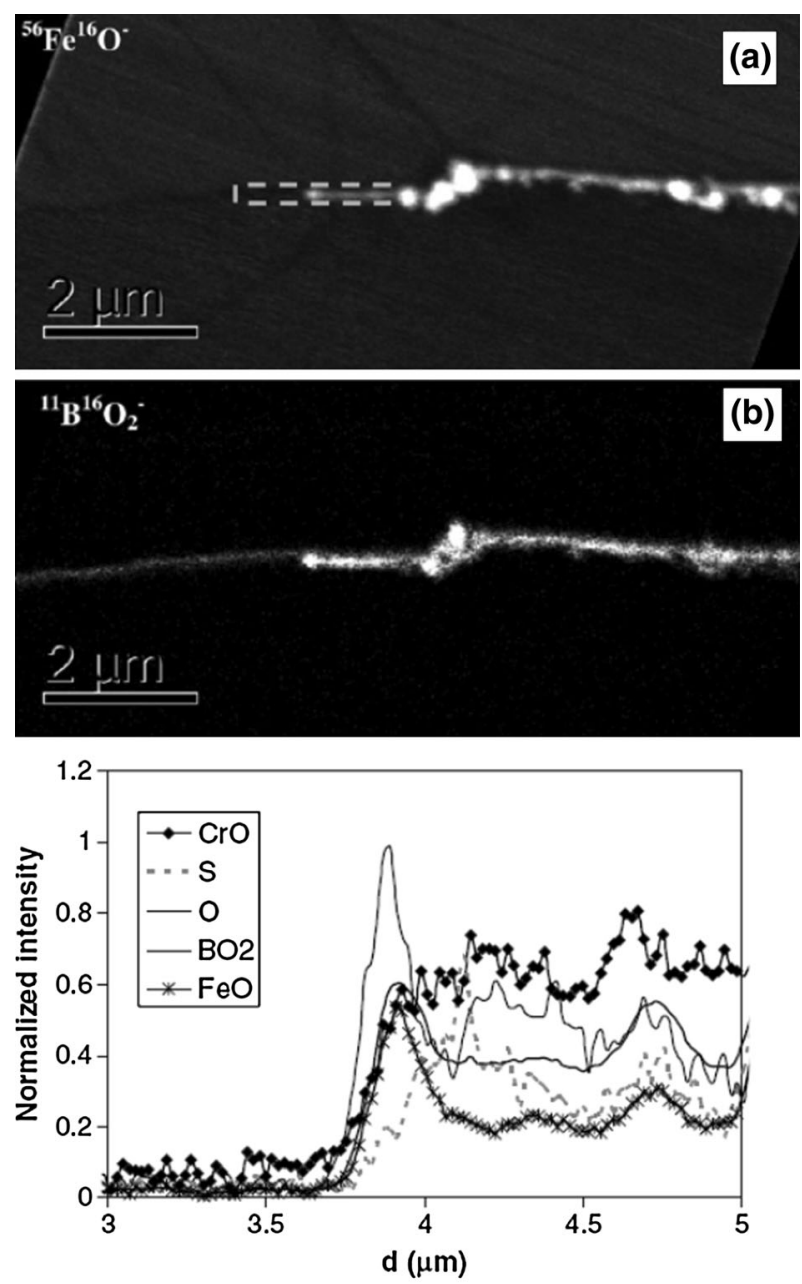

(c)

Fig. 3-Dominant crack tip region from a $20 \mathrm{pctCW}$ stainless steel sample. (a) NanoSIMS 56Fe16O - map showing the position of the line profile, (b) NanoSIMS 11B16O2 - map from the same region, and (c) NanoSIMS line profiles (normalized). Reprinted from Ref. [126], with permission from Elsevier.

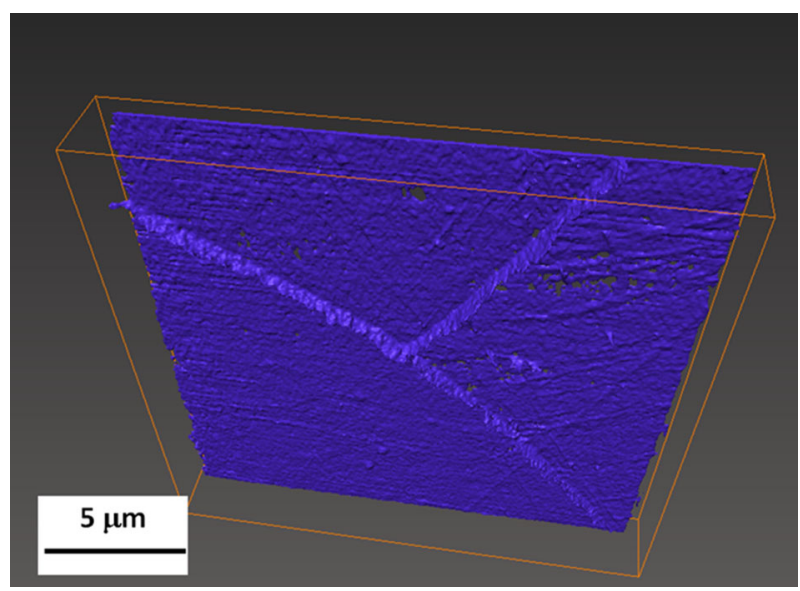

Fig. 4-3D model of the Cr-rich spinel oxide from a 304SS with prior 20 pctCW and oxidized under applied stress in simulated PWR primary conditions. Reprinted from Ref. [54] with permission from Elsevier.

\section{F. Strain Mapping with Digital Image Correlation (DIC)}

DIC has been recently applied to the characterization of deformation behavior in reactor materials which are susceptible to SCC. By using special markers on the surface of the sample, nm-resolution is achieved when mapping strain in an SEM equipped with an in situ straining stage. This technique, unlike EBSD, which based its strain mapping on lattice rotations and the calculation of geometrically necessary dislocations, ${ }^{[133]}$ is capable of registering small displacements in the lattice (e.g., individual slip events), so that it reveals even the smallest effects of deformation. ${ }^{[134-136]}$ In Figure 6, a very detailed strain map was produced by DIC on uniaxially strained $304 \mathrm{SS}$ after 7 pct elongation.

\section{G. Autoclave Testing: Effect of Inner Wall Material}

As a consequence of the higher spatial resolution and chemical sensitivity attained with the techniques described earlier, it was soon discovered that the composition of the outer oxide layers is highly dependent on the autoclave inner wall choice of material. Carette et al., ${ }^{[137]}$ who carried out oxide formation studies on Alloy 690, has for instance, shown that the formation as well as growth of this external layer depends strongly on the saturation with $\mathrm{Fe}$ and $\mathrm{Ni}$ cations. In recent years many laboratories have started testing Ni-base alloys in autoclaves made of Ni-base materials ${ }^{[138]}$ or $\mathrm{Ti}^{[139]}$ and the choice of suitable autoclaves has become an important experimental parameter. The thickness of the outer Fe- and Ni-rich oxide is drastically reduced when using $\mathrm{Ti}$ autoclaves and, in addition, Ti concentrations of up to 20 at. pct can be observed in the inner oxides.

\section{H. Key Observations}

The use of the above mentioned high-resolution characterization techniques has generated a vast amount of data at an unprecedented scale, greatly improving our phenomenological understanding of SCC. We have grouped these observations in the following categories:

\section{Surface oxides}

In order to understand the mechanisms of SCC, the oxides formed at the sample surface, along dislocations, deformation bands, grain boundaries, and cracks have to be studied in detail. The thickness of the surface protective films on stainless steels in simulated PWR primary water increases with elevating testing temperature. It has been proposed that both oxide layers (inner and outer) consist of spinel structures $\left(\mathrm{Me}_{3} \mathrm{O}_{4}\right.$, with $\mathrm{Me}=\mathrm{Fe}, \mathrm{Cr}$, and $\mathrm{Ni}$ ); they are formed by diffusion of Fe from the matrix (or in solution in some autoclaves) to the outer layer and diffusion of $\mathrm{O}$ to the alloy through the inner layer while $\mathrm{Cr}$ remains in place. ${ }^{[47,60,140]} \mathrm{Ni}$, being the most noble of all main alloying elements can be incorporated to the outer oxide in varying quantities depending on the electrochemical potential (i.e., dissolved $\mathrm{H}^{+}$), although under typical conditions it is 


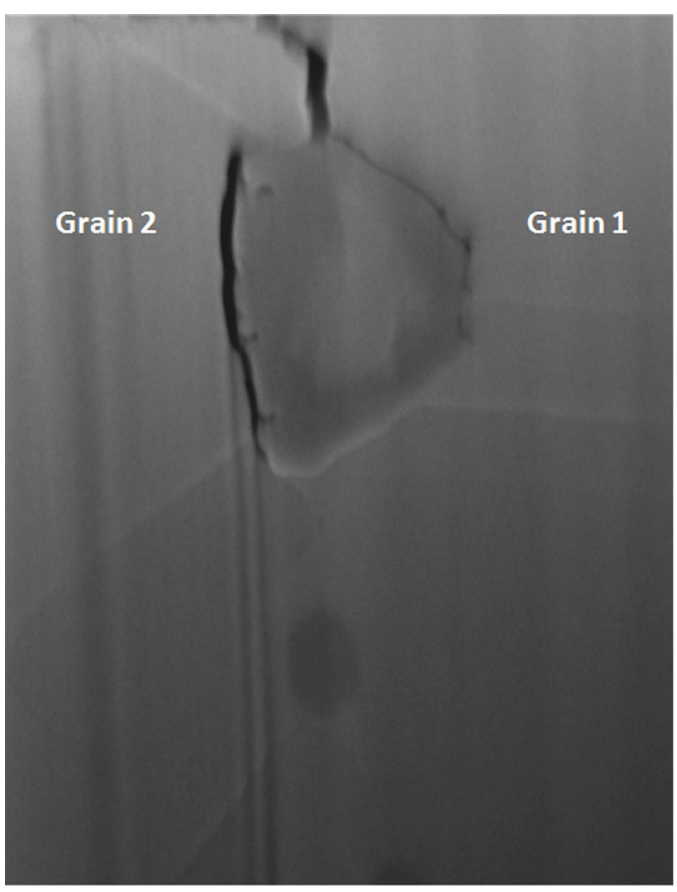

(a)

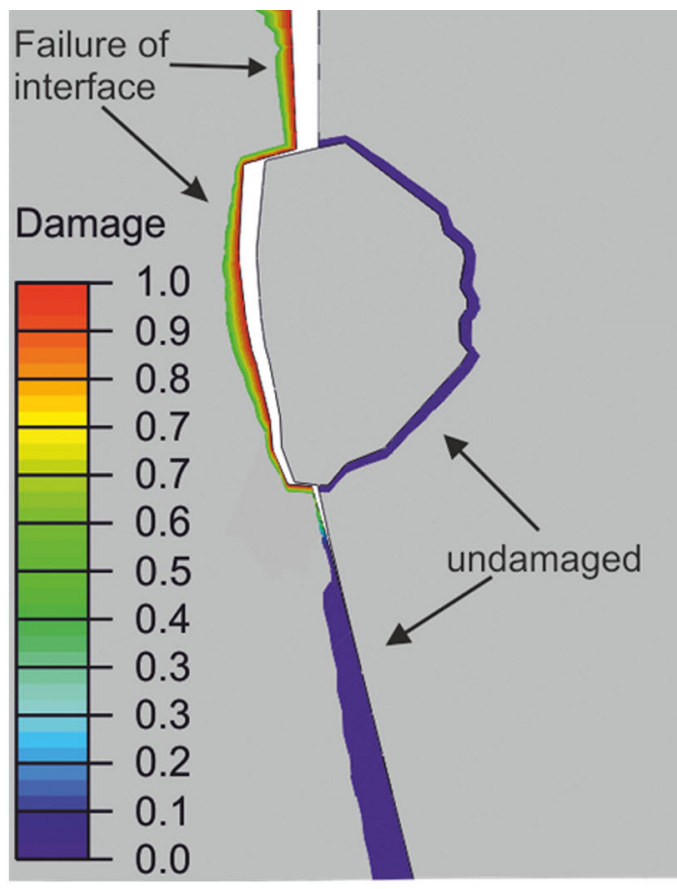

(b)

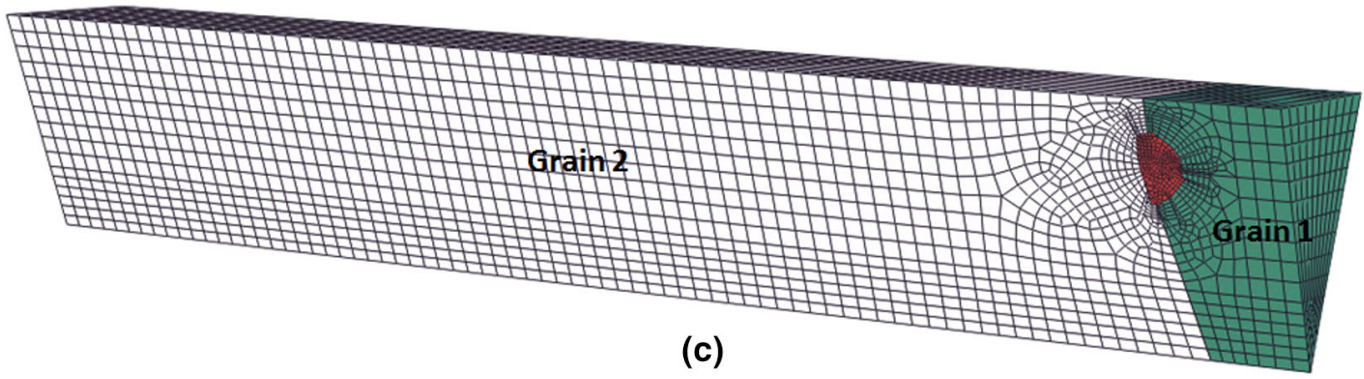

Fig. 5- (a) 2D SEM secondary electron image of the cantilever after testing. First the crack has propagated along the oxidized GB and then along the oxide/metal interface around the oxide surrounding the carbide. (b) Predicted damage obtained from the finite element model; $(c)$ Generated 3D cantilever mesh before the test. Reprinted from Ref. [91] with permission from Elsevier.

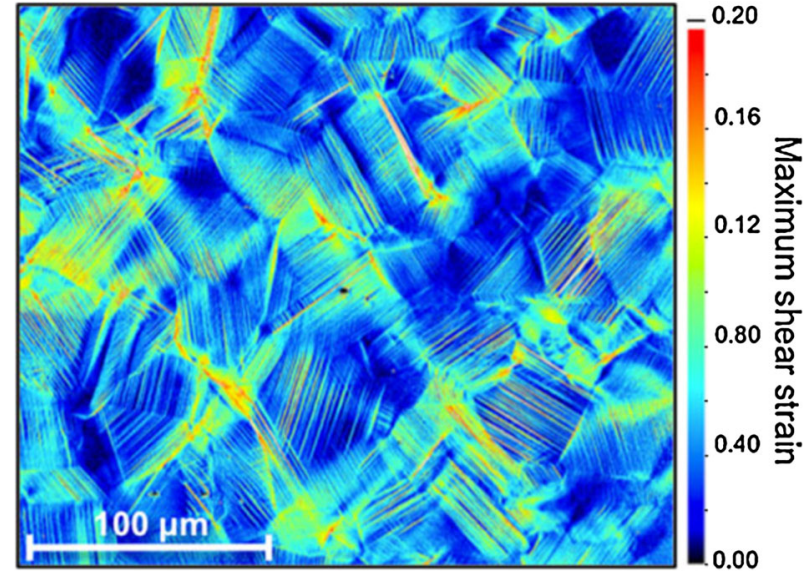

Fig. 6-Values of maximum shear strain calculated for 7 pct macroscopic elongation using sub-region of $216 \times 216 \mathrm{~nm}^{2}$. Sample: $304 \mathrm{SS}$ uniaxially strained. With kind permission from Springer Science + Business Media: $:^{[136]}$. mostly found at the oxide-metal interface. A comprehensive study by Stellwag ${ }^{[141]}$ proposes that the outer layer is formed due to the precipitation of metal ions released from the metal surface or the solution and the inner oxide grew as a result of the passivation reaction in the corrosive environment. It is generally assumed that only the inner Cr-rich spinel oxide plays an important role in corrosion resistance. ${ }^{[141-144]}$ Sennour et al..$^{[145]}$ demonstrated that the surface condition (e.g., surface defects) has an influence on the oxide, as crystallites seem to nucleate preferentially along polishing scratches present at the surface.

The Cr-rich inner layer in Ni alloys is usually thinner than $100 \mathrm{~nm}^{[146]}$ and can be divided into two sub layers - a compact $\mathrm{Cr}$ oxide layer, which is situated at the metal/oxide interface and a Cr-rich spinel-type oxide, which makes up the majority of the inner layer. ${ }^{[14]}$ Recent high-resolution oxide composition analysis by Sennour et al. ${ }^{[145]}$ in $\mathrm{Ni}$ alloys exposed to PWR primary water suggests that the protective inner layer is a spinel-type nickel chromite, $\mathrm{Ni}_{(1-x)} \mathrm{Fe}_{x} \mathrm{Cr}_{2} \mathrm{O}_{4}$, 
in which the $\mathrm{Fe}$ and $\mathrm{Ni}$ contents are dependent of their concentrations in the solution. In addition, nodules of $\mathrm{Cr}_{2} \mathrm{O}_{3}$ are observed dispersed at the oxide-metal interface. Whether this layer of $\mathrm{Cr}_{2} \mathrm{O}_{3}$ is continuous or not (more likely in Alloy 690 than in Alloy 600) will determine how resistant the alloy is to oxidation. Additionally, a Ni-rich (Cr-depleted) zone beneath the $\mathrm{Cr}$ oxide layer has been observed frequently. ${ }^{[144,146]}$

Cross-sectional TEM characterization has become a very useful tool to analyze the different oxide layer structures. $\mathrm{Ni}$ enrichment (also referred to as Cr-depleted zone) is frequently observed at the oxidemetal interface and ahead of the crack tip. Quantitative elemental analysis reported by several groups indicates that $\mathrm{Ni}$ is enriched by more than twice its bulk concentration at the oxide-metal interface. Based on the findings several research groups, ${ }^{[47,60,147]}$ a hypothesis for $\mathrm{Ni}$ enrichment and its impact on crack propagation has been proposed. While $\mathrm{Fe}$ and $\mathrm{Cr}$ oxides form easily on the free surfaces, $\mathrm{Ni}$ (being the most noble of the three) tends to be rejected by the oxide formation. Therefore, oxide structures often appear Ni depleted, while the $\mathrm{Ni}$, diffusing toward the matrix, frequently accumulates at metal-oxide interfaces or ahead of oxidized cracks and grain boundaries.

Lozano-Perez et al. ${ }^{[148]}$ used the atom probe for the first time to investigate surface oxides in stainless steels tested under simulated PWR primary water conditions. This new approach provided with an unprecedented level of detail and allowed the characterization of minor alloying elements and impurities down to levels of ppm. The outer Fe-rich spinel was found to be weakly adhered to the surface and therefore prone to fracturing during atom probe analysis. The inner $\mathrm{Cr}$-rich oxide layer was studied in detail (Figure 2) achieving a very accurate chemical quantification that also revealed the exact amount of $\mathrm{Li}$ incorporated from the primary water (up to $400 \mathrm{ppm}$ ). No B incorporation was observed. The Ni-rich layer at the oxide-metal interface was also clearly observed.

The role of prior $\mathrm{CW}$ and applied stress on surface oxidation of stainless steels revealed that, although no obvious difference could be measured regarding average surface oxidation, the story was very different when looking at localized oxidation down grain boundaries or deformation bands. The presence of deformation (in the form of dislocations) triggered localized oxidation, whether they were directly intersecting the exposed surface or piled next to a GB. In many cases, the dislocations left near the surface after grinding and polishing were enough (even they extended to depths smaller than $50 \mathrm{~nm}$ ). Applied stress enhanced even further the localized oxidation, down to depths $>10$ times bigger than the average oxidation. However, the presence of dislocations was a pre-requisite. ${ }^{[54]}$ In Figure 7, the oxidized surface of a 304SS sample with prior 20 pctCW exposed to simulated PWR primary water for 1500 hours is shown. Figure 7 shows a TEM $\mathrm{BF}$ image where, in cross-section, it can be appreciated that an inner surface oxide of $\sim 50 \mathrm{~nm}$ has grown on the left grain. On the right grain is thinner. Moreover, in this grain there are three visible deformation bands caused by the $\mathrm{CW}$. More interesting information is present in the analytical maps extracted by EFTEM. The data has been extracted and processed as described in Reference 149. The oxygen map reveals the extent of the oxidation, where the GB and the deformation bands are clearly attacked. In addition, it is also clear that smaller features are oxidized below the oxide-metal interface. Comparison with TEM BF and HREM images concluded that these features were dislocations. $\mathrm{Fe}$ is clearly depleted in all inner oxides, which are slightly richer in $\mathrm{Cr}$ than the matrix. $\mathrm{Ni}$, as mentioned before, appears enriched at all oxide-metal interfaces, including the oxidized portions of dislocations below the oxide-metal interface. As can be seen, the accumulation of Ni along the GB (and deformation bands) ahead of the oxidation front has caused the oxidation to proceed sideways, and therefore slowly. These observations have been a constant in 304, 316, and some Ni alloys when oxidized under PWR primary conditions.

Overall, it has been found that the formation of the inner oxide does not involve much $\mathrm{Cr}$ diffusion. It generally requires that around half of the original $\mathrm{Fe}$ and two-thirds of original $\mathrm{Ni}$ atoms diffuse outwards and that oxygen diffuses inwards, in order to form the inner $\mathrm{Cr}$-rich oxide. The more deformation and applied stress, the higher the mobility of the $\mathrm{Cr}$ from the neighboring matrix into the oxide (in the example of Figure 7 there are 20 pct more atoms of $\mathrm{Cr}$ in the oxide respect to the matrix). Ni mobility is also increased.

\section{Grain boundary and crack tip chemistry}

The use of site-specific sample preparation (FIB and, to a certain extent, ion beam thinning), finally allowed the characterization of selected crack tips in the TEM. This approach enabled the study of the microstructure and microchemistry in such a critical area. In some cases, cracks were found to grow in a step-wise manner, advancing after discrete nanoplasticity events which seemed to fracture portions of the GB ahead of the crack tip which were previously oxidized, as suggested by the slip-dissolution model. As can be seen in Figure 8, when looking at the elemental distributions obtained by EELS SI of a crack tip from a 304SS sample tested under PWR primary conditions, some conclusions can be drawn. Comparing the $\mathrm{O}$ and $\mathrm{Cr}$ maps $(9 \mathrm{c}$ and 9d), the location of the crack tip can be identified (indicated by a vertical arrow) as well as the presence of a Cr-rich oxide at the crack flanks. The Fe map (9e) indicates that the open crack is filled with an Fe-rich spinel oxide. The elemental Ni map (9f) clearly shows $\mathrm{Ni}$ enrichment $\left(\sim 20 \mathrm{~nm}\right.$ width) ahead of the crack tip. ${ }^{[41]}$

In $\mathrm{Ni}$ alloys, especially in Alloy 600, IG oxidation under PWR conditions is much more severe. ${ }^{[76,144,150]}$ Some SCC models (e.g., the internal oxidation model relies on these oxides being brittle and thus influencing the GB's mechanical properties).

Characterization of oxidized grain boundaries $^{[111,123,127]}$ revealed that, in most cases, the oxide front is composed of discrete oxide particles which are not interconnected, suggesting a solid state diffusion of $\mathrm{O}$. The $3 \mathrm{D}$ nature of the oxidation processes makes the atom probe an ideal technique for resolving such 

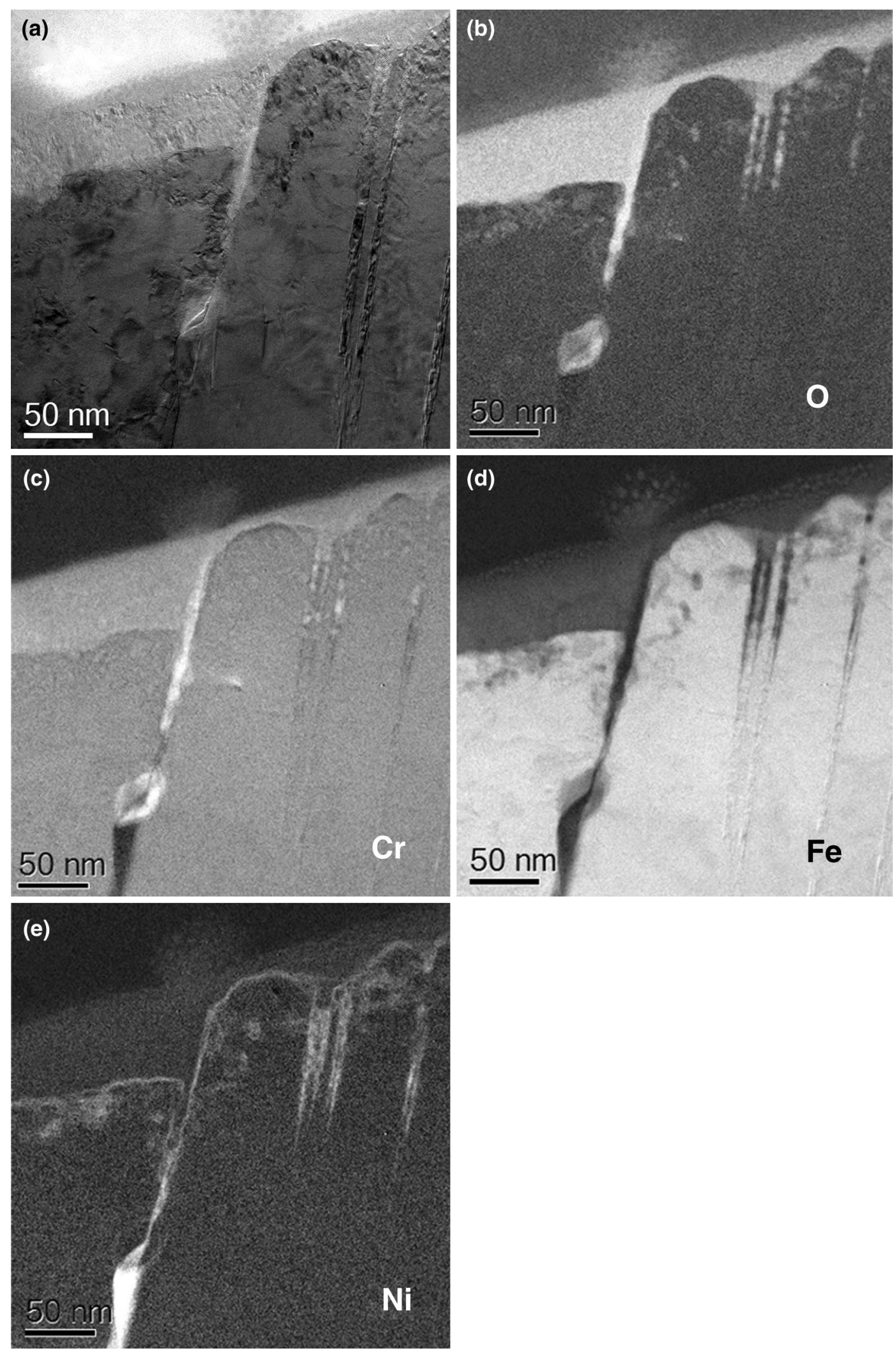

Fig. 7-TEM BF image showing a cross-sectional view of the surface of a 304SS coupon specimen with prior 20 pctCW after exposure to simulated PWR primary water for $1500 \mathrm{~h}(a)$. EFTEM maps: O K $(b), \mathrm{Cr} \mathrm{L}(c), \mathrm{Fe} \mathrm{L}(d)$, and Ni L $(e)$.

complex phenomena at the nanoscale. It has also been frequently observed that that the oxide films on the crack walls have the same structure as the films formed on the surface of the specimen. Therefore, there might be only a very small potential gradient between sample surface and the inside walls of the crack, although the 

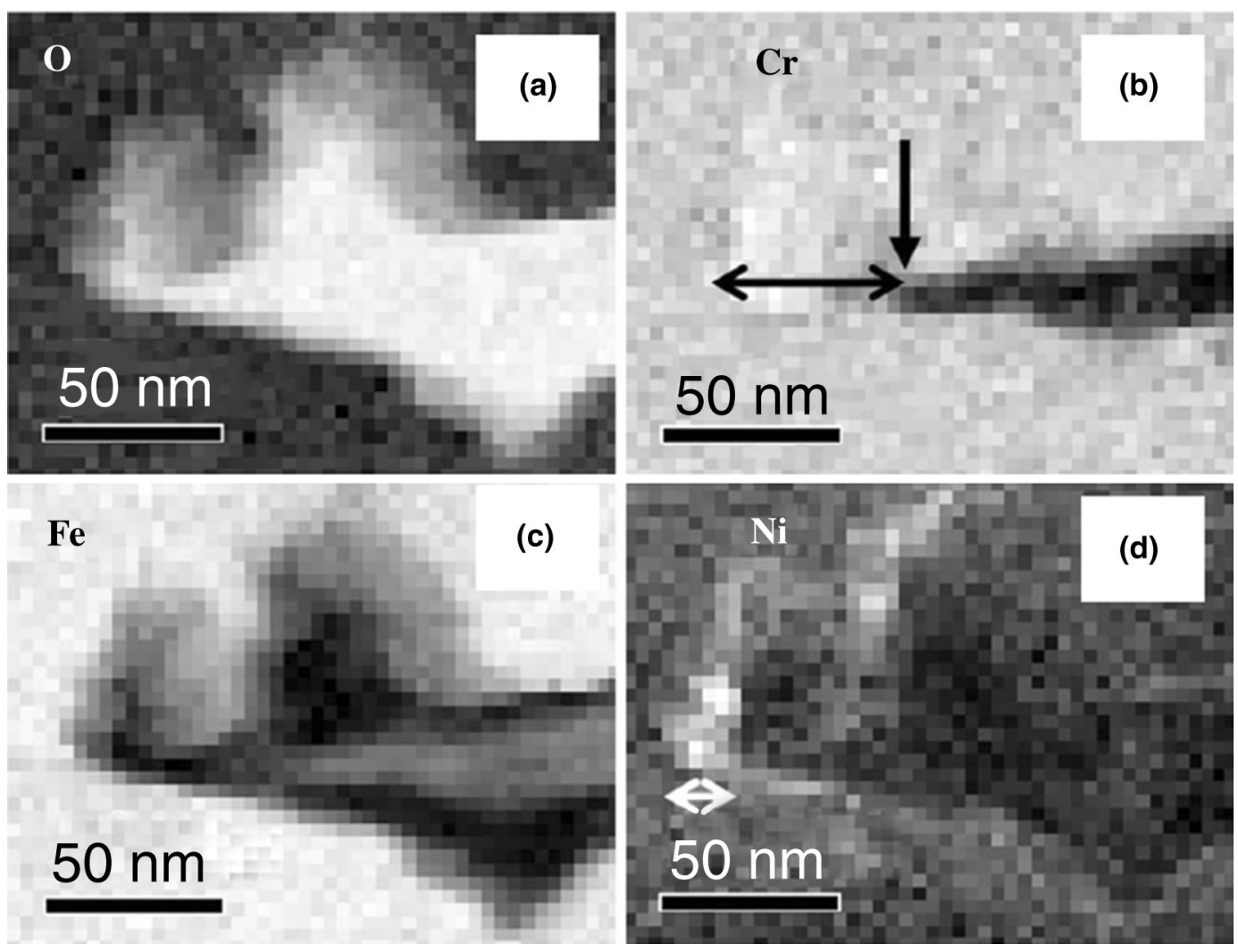

Fig. 8-EELS maps of crack tip region. (a) O K map; (b) $\mathrm{Cr} \mathrm{L}$ map: vertical arrow indicates crack tip, horizontal arrow indicates Cr oxide; (c) Fe L map; (d) Ni L map. Reprinted from Ref. [41], with permission from Elsevier.

situation might be different at the oxidized portion ahead of the crack tip.

Another important finding is the fact that oxidized grain boundaries (before they crack) are fast-diffusion paths for oxygen and hydrogen (actually faster than SCC CGRs according to Reference 151). For this reason, it is suggested that they should not be considered a rate-controlling step, as it has been suggested in the past when criticizing the internal oxidation mechanism. $\mathrm{Cr}$ diffusion is suggested as the rate-controlling step instead. Thus, the time required to form a protective oxide layer seems more likely to relate to the observed CGRs.

\section{Grain boundary strength}

In the last few years, different groups have reported on the capability of mechanically testing individual grain boundaries. This is particularly interesting when the GB in question is oxidized, allowing the determination of the stress required to fracture the oxidized GB and thus providing the necessary data to validate/ disprove SIO mechanisms. Fujii and Fukuya ${ }^{[132]}$ devised a very ingenious way of measuring these stresses by devising a micro-tensile experiment inside a FIB. He found that stresses as low as $300 \mathrm{MPa}$ could fracture Alloy 600 oxidized grain boundaries. Dugdale, ${ }^{[91]}$ which focussed on the micromechanical testing of oxidized GBs via nanoindentation of microcantilevers, reported slightly higher values of $1 \mathrm{GPa}$ for similar samples. In addition, it was found that crack paths were modified by the presence of carbides along the GBs. The carbides did not oxidize themselves but were surrounded by a Cr-depleted region, which oxidized preferentially. However, this oxidized layer was never observed to fracture during the tests. By studying the effect of IG carbides through finite element modeling, it was suggested that carbides might have a minor strengthening effect. The authors proposed that the rather complex crack paths caused by carbides, as compared to the rather straight crack paths when no carbides are present, to be the origin of the strengthening.

\section{CONCLUSIONS}

The arrival of new characterization techniques to the range of tools available to study SCC is finally allowing the acquisition of high-resolution data from the key regions of interest (e.g., Surface or crack tips). This data, in the form of direct observations, can easily validate or disprove models or mechanisms that have remained controversial for decades. Thus, a better understanding of the processes observed at the nanoscale will ultimately lead to modifications, additions, or proposals for more realistic models.

Next a summary of the key findings extracted from the high-resolution (direct) characterization discussed in this review is presented. These findings should be accounted for by any proposed SCC model. 


\section{A. Oxidation}

1. Outer oxides are of magnetite-type, usually rich in $\mathrm{Fe}$ and $\mathrm{Ni}$. Inner oxides are chromite-type spinels, always rich in $\mathrm{Cr}$. In high $\mathrm{Cr}$-containing alloys (e.g., Alloy 690), chromia can form near the oxidemetal interface. $[141,144,145]$

2. IG oxidation is enhanced by $\mathrm{CW}$ (particularly in SS) and inhibited by increasing levels of $\mathrm{Cr}$ in the alloy. ${ }^{[41]}$ The oxide front, as observed by APT, appears discrete and formed by a discontinuous network of oxides of similar composition to the "bulk" continuous IG oxide. ${ }^{[148,152]}$ This would support a solid state diffusion of $\mathrm{O}$ down dislocations.

3. Enhanced oxidation is observed along grain boundaries, twin deformation bands, and dislocations. Applied stress further enhances oxidation rates. ${ }^{[54,111,153]}$

4. $\mathrm{Li}$ from the primary water is incorporated to all Cr-rich oxides in concentrations of up to several hundred ppm. B has not been detected in any of the oxides. IG oxides seem to push away the B previously segregated to the grain boundaries. ${ }^{[125,126,148]}$

5. As oxidation progresses, both on the surface and along grain boundaries, $\mathrm{Ni}$ is pushed away from the inner Cr-rich spinels and segregates into a Ni-rich region at the oxide-metal interface. ${ }^{[41,111]}$ This Nirich region can cause a local GB migration. ${ }^{[127]}$

6. Voids are frequently observed in the IG oxides and, in some cases (where stresses are higher), ahead of the oxide front. ${ }^{[64,152,154]}$

7. Austenitic stainless steels and $\mathrm{Ni}$ alloys have the same crystal structure and exhibit similar mechanical properties. However, the oxidation behavior is different. Alloy 600, for example, exhibits only very shallow surface oxides, about one order of magnitude thinner than 304 stainless steel. However, GBs in Alloy 600 will oxidize to a much greater depth. Since observed CGRs at PWR conditions are similar, either initial IG oxidation rates are similar or IG oxidation does not play a crucial role.

\section{B. Hydrogen}

- Very little high-resolution evidence exists of $\mathrm{H}$ associated with SCC. Recent APT work has identified trapped $\mathrm{H}$ associated with the $\mathrm{Ni}$-enriched region at the oxide-metal interface. This enrichment is only possible via substitutional diffusion of $\mathrm{Ni}$, which requires vacancies that might be stabilized by trapped $\mathrm{H}^{[152,153]}$

\section{Cracking}

1. SCC is mostly IG under PWR primary conditions. For $\mathrm{SS}$, some level of $\mathrm{CW}$ is required to activate crack growth. ${ }^{[46,60,155]}$

2. Fracture surfaces are observed to have a step-like structure, suggesting that some nanoplasticity has occurred as the crack advances. ${ }^{[41,155]}$ The step patterns on the fracture surfaces suggest that slip plays a role in the formation of the crack. It is possible that slip leads to crack advance or it could be responsible for crack opening. Alternate slip could lead to both at the same time.

3. IG oxides are brittle (at least in air). Stresses between 300 and $1000 \mathrm{MPa}$ are required to fracture them. These values are not far from observed SCC sustained crack growth thresholds. ${ }^{[91,132]}$ Oxidized grain boundaries can break under stress (applied or residual).

Taking into account all these observations, it becomes apparent that more than one mechanism is needed to explain SCC in PWRs. Oxidation ahead of crack tips and IG oxidation of both $\mathrm{Ni}$ alloys and stainless steels have been demonstrated. However, the morphology of the crack tip and crack flanks suggests that local plasticity has occurred. Local deformation is often observed along slip directions, with periodic steps observed on the fracture surfaces. Hydrogen has also been observed trapped in the region around the crack tip, but its exact contribution its still unclear.

\section{ACKNOWLEDGMENTS}

The authors are grateful to INSS (Japan), EDF (France), Areva (France), and EPRI (US) for supporting their SCC-related research.

\section{REFERENCES}

1. IAEA: Ref. Data Ser., 2013, vol. 2013, pp. 86-87.

2. T. Satoh, T. Nakazato, S. Moriya, S. Suzuki, and T. Shoji: $J$. Nucl. Mater., 1998, vols. 258-263, pp. 2054-58.

3. P.M. Scott and M. Le Calvar: in Proceedings of the Sixth International Symposium on Environmental Degradation of Materials in Nuclear Power Systems - Water Reactors, 1993, pp. 657-65.

4. R.W. Staehle and Z. Fang: in Proceedings of the Ninth International Symposium on Environmental Degradation of Materials in Nuclear Power Systems-Water Reactors, 1999, pp. 69-78.

5. T. Magnin, A. Chambreuil, and J.P. Chateau: Int. J. Fract., 1996, vol. 79 (2), pp. 147-63.

6. M.M. Hall, Jr: Corros. Sci., 2008, vol. 50, pp. 2902-05.

7. M.M. Hall, Jr: Corros. Sci., 2009, vol. 51, pp. 225-33.

8. P.M. Scott and P. Combrade: in 11th International Conference on Environmental Degradation of Materials in Nuclear Power Systems-Water Reactors, 2003, pp. 29-38.

9. K. Arioka, T. Yamada, T. Terachi, and T. Miyamoto: Corrosion, 2008, vol. 64, pp. 691-706.

10. R.W. Staehle: in Canadian Nuclear Society-13th International Conference on Environmental Degradation of Materials in Nuclear Power Systems 2007, 2007, vol. 3, pp. 1877-957.

11. R.W. Staehle: in Proceedings of the International Symposium on Research for Ageing Management of Light Water Reactors, 2007, pp. 7-23.

12. T. Shoji, Z. Lu, and Q. Peng: Stress Corrosion Cracking: Theory and Practice, Woodhead, Cambridge, 2011, pp. 245-72.

13. V.S. Raja and T. Shoji: Materials, Woodhead, Cambridge, 2011, pp. $792-814$

14. E.M. Gutman: Corros. Sci., 2007, vol. 49, pp. 2289-302.

15. H.L. Logan: J. Res. Natl. Bur. Stand., 1952, vol. 48 (2), pp. 99 113.

16. R.C. Newman and C. Healey: Corros. Sci., 2007, vol. 49, pp. $4040-50$.

17. D.A. Vermilyea: J. Electrochem. Soc., 1972, vol. 119, pp. 405-07. 
18. F.P. Ford: Corros. Process., 1982, vol. 1, pp. 271-96.

19. P.L. Andresen and F.P. Ford: Mater. Sci. Eng. A, 1988, vol. A103, pp. 167-84.

20. D.A. Jones: Metall. Trans. A, 1985, vol. 16A, pp. 1133-41.

21. P.L. Andresen: Proc. Corros., 1996, vol. 96, pp. 128-45.

22. R.C. Newman: Corrosion, 1994, vol. 50, pp. 682-86.

23. S. Qian, R.C. Newman, R.A. Cottis, and K. Sieradzki: Corros. Sci., 1990, vol. 31, pp. 621-26.

24. A. Turnbull: Corros. Sci., 1993, vol. 34, pp. 921-60.

25. M.M. Hall, Jr: Corros. Sci., 2009, vol. 51, pp. 1103-06.

26. M. Vankeerberghen, G. Weyns, S. Gavrilov, B. Martens, and J. Deconinck: J. Nucl. Mater., 2009, vol. 384, pp. 274-85.

27. A.R. Troiano: Trans. ASM, 1960, vol. 52, pp. 54-80.

28. L.L. Shreir: Werkstoffkunde Und Korrosion, 1970, vol. 21, pp. 613-29.

29. S.P. Lynch: Acta Metall., 1988, vol. 36, pp. 2639-61.

30. R.A. Oriani: Corrosion, 1987, vol. 43, pp. 390-97.

31. T. Magnin, A. Chambreuil, and B. Bayle: Acta Mater., 1996, vol. 44, pp. 1457-70.

32. C.D. Beachem: Metall. Trans. A, 1972, vol. 3A, pp. 441-55.

33. D.O. Hayward: Chemisorption, 2nd ed., Butterworths, London, 1964.

34. C.B. Gilpin, D.H. Paul, S.K. Asunmaa, and N.A. Tiner: $A d v$. Electr. Metallogr., 1966, vol. 6, pp. 7-20.

35. A. Cracknell and N.J. Petch: Acta Metall., 1955, vol. 3, pp. 18689.

36. G.M. Bond, I.M. Robertson, and H.K. Birnbaum: Acta Metall., 1988, vol. 36, pp. 2193-97.

37. H.K. Birnbaum and P. Sofronis: Mater. Sci. Eng. A, 1994, vol. 176, pp. 191-202.

38. M.L. Martin, B.P. Somerday, R.O. Ritchie, P. Sofronis, and I.M. Robertson: Acta Mater., 2012, vol. 60, pp. 2739-45.

39. R.B. Rebak and Z. Szklarska-Smialowska: Corros. Sci., 1996, vol. 38 (6), pp. 971-88.

40. L.E. Thomas and S.M. Bruemmer: in Proceedings of the Ninth International Symposium on Environmental Degradation of Materials in Nuclear Power Systems-Water Reactors, 1999, pp. 41-47.

41. S. Lozano-Perez, T. Yamada, T. Terachi, M. Schröder, C.A. English, G.D.W. Smith, C.R.M. Grovenor, and B.L. Eyre: Acta Mater., 2009, vol. 57, pp. 5361-81.

42. A.J. McEvily and I. Le May: Mater. Charact., 1991, vol. 26, pp. $253-68$.

43. A. Turnbull: Br. Corros. J., 1992, vol. 27, pp. 271-89.

44. A.J. Sedriks: Corrosion Testing Made Easy, NACE International, Houston, TX, 1990.

45. F. Scenini, R.C. Newman, R.A. Cottis, and R.J. Jacko: Corrosion, 2008, vol. 64, pp. 824-35.

46. K. Arioka, T. Yamada, T. Terachi, and G. Chiba: Corrosion, 2006, vol. 62, pp. 568-75.

47. T. Terachi, K. Fujii, and K. Arioka: J. Nucl. Sci. Technol., 2005, vol. 42, pp. 225-32.

48. S.M. Bruemmer, M.J. Olszta, M.B. Toloczko, and L.E. Thomas: in 15th International Conference on Environmental Degradation of Materials in Nuclear Power Systems-Water Reactors 2011, 2011, vol. 1, pp. 288-301.

49. J.C. Langevoort, T. Fransen, and P.J. Gellings: Oxid. Met., 1984, vol. 21, pp. 271-84.

50. J.C. Langevoort, I. Sutherland, L.J. Hanekamp, and P.J. Gellings: Appl. Surf. Sci., 1987, vol. 28, pp. 167-79.

51. M. Mizouchi, Y. Yamazaki, Y. Lijima, and K. Arioka: Mater. Trans., 2004, vol. 45, pp. 2945-50.

52. M.J. Olszta, D.K. Schreiber, L.E. Thomas, and S.M. Bruemmer: in 15th International Conference on Environmental Degradation of Materials in Nuclear Power Systems-Water Reactors 2011, 2011, vol. 1, pp. 317-28.

53. K. Arioka, T. Yamada, T. Terachi, and G. Chiba: Corrosion, 2007, vol. 63 (12), pp. 1114-23.

54. S. Lozano-Perez, K. Kruska, I. Iyengar, T. Terachi, and T. Yamada: Corros. Sci., 2012, vol. 56, pp. 78-85.

55. R.B. Rebak, Z. Xia, and Z. Szklarska-Smialowska: Corrosion, 1995, vol. 51, pp. 689-97.

56. W.C. Moshier and C.M. Brown: Corrosion, 2000, vol. 56, pp. 307-20.
57. C. Guerre, O. Raquet, E. Herms, S. Marie, and M. Le Calvar: in Canadian Nuclear Society-13th International Conference on Environmental Degradation of Materials in Nuclear Power Systems 2007, 2007, vol. 1, pp. 676-99.

58. T. Terachi, T. Yamada, T. Miyamoto, and K. Arioka: J. Nucl. Mater., 2012, vol. 426, pp. 59-70.

59. T. Terachi, T. Yamada, G. Chiba, and K. Arioka: Corrosion 2007, 2007, Paper 7605.

60. K. Arioka, T. Yamada, T. Terachi, and G. Chiba: Corrosion, 2007, vol. 63, pp. 1114-23.

61. K. Arioka: in 16th International Conference on Environmental Degradation of Materials in Nuclear Power Systems-Water Reactors, 2013, vol. 1, pp. 256-63.

62. K. Arioka, T. Miyamoto, T. Yamada, and T. Terachi: Corrosion, 2010, vol. 66, pp. 0150081-84.

63. K. Arioka, T. Miyamoto, T. Yamada, and T. Terachi: in 14th International Conference on Environmental Degradation of Materials in Nuclear Power Systems Water Reactors 2009, 2009, vol. 2, pp. 895-909.

64. K. Arioka, T. Miyamoto, T. Yamada, and T. Terachi: in 15th International Conference on Environmental Degradation of Materials in Nuclear Power Systems-Water Reactors 2011, 2011, vol. 1, pp. 52-66.

65. R. Bandy and D. van Rooyen: Nucl. Eng. Des., 1985, vol. 86, pp. $49-56$.

66. T. Terachi, N. Totsuka, T. Yamada, T. Miyamoto, M. Ozawa, and K. Nakata: in NACE-International Corrosion Conference Series, 2009, pp. 146-51.

67. B. Alexandreanu, Y. Yang, Y. Chen, and W.J. Shack: in 14th International Conference on Environmental Degradation of Materials in Nuclear Power Systems Water Reactors 2009, 2009, vol. 1, pp. 239-50.

68. S. Yamazaki, Z. Lu, Y. Ito, Y. Takeda, and T. Shoji: Corros. Sci., 2008, vol. 50, pp. 835-46.

69. K. Tsutsumi and T. Couvant: in 15th International Conference on Environmental Degradation of Materials in Nuclear Power Systems-Water Reactors 2011, 2011, vol. 1, pp. 39-50.

70. D.J. Paraventi and W.C. Moshier: in Canadian Nuclear Society-13th International Conference on Environmental Degradation of Materials in Nuclear Power Systems 2007, 2007, vol. 2, pp. 766-81.

71. P.L. Andresen and M.M. Morra: Corrosion, 2008, vol. 64, pp. 15-29.

72. F. Delabrouille, L. Legras, F. Vaillant, P. Scott, B. Viguier, and E. Andrieu: in Proceedings of the 12th International Conference on Environmental Degradation of Materials in Nuclear Power Systems-Water Reactors, 2006, pp. 903-11.

73. T.M. Angeliu and G.S. Was: J. Electrochem. Soc., 1993, vol. 140, pp. 1877-83.

74. T. Yonezawa, H. Kanasaki, M. Taneike, Y. Sakaguchi, S. Ooki, H. Tezuka, K. Takamori, and S. Suzuki: in 14th International Conference on Environmental Degradation of Materials in Nuclear Power Systems Water Reactors 2009, 2009, vol. 2, pp. 1274-88.

75. J.J. Kai, C.H. Tsai, T.A. Huang, and M.N. Liu: Metall. Trans. A, 1989, vol. 20A, pp. 1077-88.

76. R.C. Newman, T.S. Gendron, and P.M. Scott: in Proceedings of the Ninth International Symposium on Environmental Degradation of Materials in Nuclear Power Systems-Water Reactors, 1999, pp. 79-95.

77. T. Watanabe: Res. Mech., 1984, vol. 11, pp. 47-84.

78. S.M. Bruemmer and G.S. Was: J. Nucl. Mater., 1994, vol. 216, pp. 348-63.

79. B. Alexandreanu, B. Capell, and G.S. Was: Mater. Sci. Eng. A, 2001, vol. 300, pp. 94-104.

80. B. Alexandreanu and G.S. Was: Scripta Mater., 2006, vol. 54, pp. 1047-52.

81. E.A. West, M.D. McMurtrey, Z. Jiao, and G.S. Was: Metall. Mater. Trans. A, 2012, vol. 43A, pp. 136-46.

82. V.Y. Gertsman and S.M. Bruemmer: Acta Mater., 2001, vol. 49 (9), pp. 1589-98.

83. A. Aguilar, J.L. Albarran, H.F. Lopez, and L. Martinez: Mater. Lett., 2007, vol. 61, pp. 274-77.

84. J.M. Sarver, J.R. Crum, and W.L. Mankins: Corrosion, 1988, vol. 44, pp. 288-89. 
85. K. Yamanaka: in Proceedings of the Sixth International Symposium on Environmental Degradation of Materials in Nuclear Power Systems-Water Reactors, 1993, vol. 1, pp. 105-09.

86. G.S. Was, J.K. Sung, and T.M. Angeliu: Metall. Trans. A, 1992, vol. 23A, pp. 3343-59.

87. J.L. Hertzberg and G.S. Was: Metall. Mater. Trans. A, 1998, vol. 29A, pp. 1035-46.

88. P.H. Hoang, A. Gangadharan, and S.C. Ramalingam: Nucl. Eng. Des., 1998, vol. 181, pp. 209-19.

89. S.M. Bruemmer, L.A. Charlot, and C.H. Henager, Jr: Corrosion, 1988, vol. 44, pp. 782-88.

90. J.J. Kai, C.H. Tsai, and G.P. Yu: Nucl. Eng. Des., 1993, vol. 144, pp. 449-57.

91. H. Dugdale, D.E.J. Armstrong, E. Tarleton, S.G. Roberts, and S. Lozano-Perez: Acta Mater., 2013, vol. 61, pp. 4707-13.

92. D. Feron and J. Olive: Corrosion Issues in Light Water Reactors: Stress Corrosion Cracking, Published for the European Federation of Corrosion by Woodhead Publishing and Maney Publishing on behalf of the Institute of Materials, Minerals \& Mining, Cambridge, 2007.

93. T. Terachi and K. Arioka: NACE Int. Corr. Conf. Ser., 2006, vol. 1, Paper 066081.

94. T. Terachi and K. Arioka: in Proceedings of Conference on Water Chemistry of Nuclear Reactor Systems, 2004, pp. 128-35.

95. P.L. Andresen, P.W. Emigh, M.M. Morra, and J. Hickling: in Proceedings of the Twelfth International Conference on Environmental Degradation of Materials in Nuclear Power Systems-Water Reactors, 2005, pp. 989-1008.

96. D.S. Morton, S.A. Attanasio, G.A. Young, P.L. Andresen, and T.M. Angeliu: in Proceedings of the Corrosion 2001 Conference, 2001, vol. 1, pp. 1117-24.

97. T. Cassagne, F. Vaillant, and P. Combrade: in Proceedings of the Eighth International Symposium on Environmental Degradation of Materials in Nuclear Power Systems-Water Reactors, 1997, vol. 1, pp. 307-11.

98. N. Totsuka, Y. Nishikawa, M. Kamaya, and N. Nakajima: in International Symposium on the Mechanisms of Materials Degradation and Non-Destructive Evaluation in LWR, 2002, vol. 1, pp. 35-44.

99. N. Totsuka and Z. Szklarska-Smialowska: Corrosion, 1988, vol. 44, pp. 124-26.

100. B.M. Capell and G.S. Was: Metall. Mater. Trans. A, 2007, vol. 38A, pp. 1244-59.

101. R.W. Staehle and J.A. Gorman: Corrosion, 2003, vol. 59, pp. 931-94.

102. L.E. Thomas, L.A. Charlot, and S.M. Bruemmer: in New Techniques for Characterizing Corrosion and Stress Corrosion. TMS, Warrendale, PA, 1996, vii, pp. 329-53.

103. L.E. Thomas and S.M. Bruemmer: Corrosion, 2000, vol. 56 (6), pp. $572-87$.

104. Y. Huang, S. Lozano-Perez, J.M. Titchmarsh, M.J. Jenkins, and K. Fujii: IoP Conf. Ser., 2001, vol. 168, pp. 203-06.

105. S. Lozano-Perez, Y. Huang, R. Langford, and J.M. Titchmarsh: IoP Conf. Ser., 2001, vol. 168, pp. 191-95.

106. S. Lozano-Perez: Micron, 2008, vol. 39, pp. 320-28.

107. D.B. Williams and C.B. Carter: Transmission Electron Microscopy-A Textbook for Materials Science, Springer, New York, NY, 2009

108. W.J. Nisbet, G.W. Lorimer, and R.C. Newman: Corros. Sci., 1993, vol. 35, pp. 457-69.

109. Y. Nemoto, Y. Miwa, M. Kikuchi, Y. Kaji, T. Tsukada, and H. Tsuji: J. Nucl. Sci. Technol., 2002, vol. 39, pp. 996-1001.

110. S. Lozano-Perez, P. Rodrigo, and L.C. Gontard: J. Nucl. Mater., 2011, vol. 408, pp. 289-95.

111. K. Kruska, S. Lozano-Perez, D.W. Saxey, T. Terachi, T. Yamada, and G.D.W. Smith: Corros. Sci., 2012, vol. 63, pp. 225-33.

112. T. Terachi, T. Yamada, T. Miyamoto, K. Arioka, and K. Fukuya: J. Nucl. Sci. Technol., 2008, vol. 45, pp. 975-84.

113. K. Fujii, K. Fukuya, and N. Nakajima: in Proceedings of the 3rd International Symposium on Material Chemistry in Nuclear Environment, 2003, vol. 1, pp. 262-67.

114. C. Guerre, P. Laghoutaris, J. Chêne, L. Marchetti, R. Molins, C. Duhamel, and M. Sennour: in 15th International Conference on Environmental Degradation of Materials in Nuclear Power Systems-Water Reactors 2011, 2011, vol. 2, pp. 1397-408.
115. T.F. Kelly and M.K. Miller: Rev. Sci. Instrum., 2007, vol. 78, pp. 031101-09.

116. L. Yao, B. Gault, J.M. Cairney, and S.P. Ringer: Philos. Mag. Lett., 2010, vol. 90, pp. 121-29.

117. A. Cerezo, P. Clifton, M.J. Galtrey, C.J. Humphreys, T.F. Kelly, D.J. Larson, S. Lozano-Perez, E.A. Marquis, R.A. Oliver, G. Sha, K. Thompson, and M. Zandbergen: Mater. Today, 2007, vol. 10 , pp. $36-42$.

118. E.A. Marquis, P. Choi, F. Danoix, K. Kruska, S. Lozano-Perez, D. Ponge, D. Raabe, and C.A. Williams: Microsc. Today, 2012, vol. 20 , pp. $44-48$

119. J. Takahashi, K. Kawakami, Y. Yamaguchi, and M. Sugiyama: Ultramicroscopy, 2007, vol. 107, pp. 744-49.

120. J.M. Cairney, D.W. Saxey, D. McGrouther, and S.P. Ringer: Physica B, 2007, vol. 394, pp. 267-69.

121. M.K. Miller and K.F. Russell: Ultramicroscopy, 2007, vol. 107, pp. 761-66.

122. D.W. Saxey, J.M. Cairney, D. McGrouther, T. Honma, and S.P. Ringer: Ultramicroscopy, 2007, vol. 107, pp. 756-60.

123. M.J. Olszta, D.K. Schreiber, L.E. Thomas, and S.M. Bruemmer: in 15th International Conference on Environmental Degradation of Materials in Nuclear Power Systems-Water Reactors 2011, 2011, vol. 2, pp. 1422-35.

124. C. Conty: Microsc. Microanal., 2001, vol. 7, pp. 142-49.

125. S. Lozano-Perez, M. Schröder, T. Yamada, T. Terachi, C.A. English, and C.R.M. Grovenor: Appl. Surf. Sci., 2008, vol. 255, pp. 1541-43.

126. S. Lozano-Perez, M.R. Kilburn, T. Yamada, T. Terachi, C.A. English, and C.R.M. Grovenor: J. Nucl. Mater., 2008, vol. 374, pp. 61-68.

127. D.K. Schreiber, M.J. Olszta, D.W. Saxey, K. Kruska, K.L. Moore, S. Lozano-Perez, and S.M. Bruemmer: Microsc. Microanal., 2013, vol. 19, pp. 676-87.

128. L. Babout, T.J. Marrow, D. Engelberg, and P.J. Withers: Mater. Sci. Technol., 2006, vol. 22, pp. 1068-75.

129. A. King, G. Johnson, D. Engelberg, W. Ludwig, and J. Marrow: Science, 2008, vol. 321, pp. 382-85.

130. T.J. Marrow, L. Babout, A.P. Jivkov, P. Wood, D. Engelberg, N. Stevens, P.J. Withers, and R.C. Newman: J. Nucl. Mater., 2006, vol. 352, pp. 62-74.

131. S. Lozano-Perez (ed.): Understanding and Mitigating Ageing in Nuclear Power Plants: Materials and Operational Aspects of Plant Life Management (PLiM), vol. 1, 1st ed., Woodhead, Philadelphia, 2010, pp. 389-406.

132. K. Fujii and K. Fukuya: Mater. Trans. A, 2011, vol. 52A, pp. 2024.

133. A.J. Wilkinson, G. Meaden, and D.J. Dingley: Superlattices Microstruct., 2009, vol. 45, pp. 285-94.

134. F. Léonard, F. Di Gioacchino, R.A. Cottis, F. Vaillant, J.Q. Da Fonseca, F. Carrette, and G. Ilevbare: in 15th International Conference on Environmental Degradation of Materials in $\mathrm{Nu}$ clear Power Systems-Water Reactors 2011, 2011, vol. 3, pp. $1640-52$.

135. D. Wright, F. Di Gioacchino, F. Scenini, J.Q. Da Fonseca, S. Nouraei, K. Mottershead, and D. Tice: in 15th International Conference on Environmental Degradation of Materials in Nuclear Power Systems-Water Reactors 2011, 2011, vol. 3, pp. 2205-16.

136. F. Di Gioacchino and J. Quinta da Fonseca: Exp. Mech., 2013, vol. 53, pp. 743-54.

137. F. Carrette, M.C. Lafont, G. Chatainier, L. Guinard, and B. Pieraggi: Surf. Interface Anal., 2002, vol. 34, pp. 135-38.

138. C. Sun, R. Hui, W. Qu, and S. Yick: Corros. Sci., 2009, vol. 51, pp. 2508-23.

139. K. Kruska, D.W. Saxey, T. Terachi, T. Yamada, P. Chou, O. Calonne, L. Fournier, G.D.W. Smith, and S. Lozano-Perez: MRS Online Proc. Libr., 2013, vol. 1514, pp. 107-18.

140. T. Miyazawa, T. Terachi, S. Uchida, T. Satoh, T. Tsukada, Y. Satoh, Y. Wada, and H. Hosokawa: J. Nucl. Sci. Technol., 2006, vol. 43, pp. 884-95.

141. B. Stellwag: Corros. Sci., 1998, vol. 40, pp. 337-70.

142. Z. Szklarska-Smialowska, Z. Szklarska-Smialowska, K. Chou, and Z. Xia: Corros. Sci., 1991, vol. 32, pp. 609-19.

143. R.L. Tapping, R.D. Davidson, E. McAlpine, and D.H. Lister: Corros. Sci., 1986, vol. 26, pp. 563-73. 
144. P. Combrade, P.M. Scott, M. Foucault, E. Andrieu, and P. Marcus: in Proceedings of the Twelfth International Conference on Environmental Degradation of Materials in Nuclear Power Systems-Water Reactors, 2005, pp. 883-90.

145. M. Sennour, L. Marchetti, F. Martin, S. Perrin, R. Molins, and M. Pijolat: J. Nucl. Mater., 2010, vol. 402, pp. 147-56.

146. J. Panter, B. Viguier, J. Cloué, M. Foucault, P. Combrade, and E. Andrieu: J. Nucl. Mater., 2006, vol. 348, pp. 213-21.

147. S.M. Bruemmer and L.E. Thomas: Mater. Res. Soc. Symp. Proc., 2010, vol. 1264, pp. 159-70.

148. S. Lozano-Perez, D.W. Saxey, T. Yamada, and T. Terachi: Scripta Mater., 2010, vol. 62, pp. 855-58.

149. S. Lozano-Perez, V. de Castro Bernal, and R.J. Nicholls: Ultramicroscopy, 2009, vol. 109, pp. 1217-28.

150. P.M. Scott: Corrosion, 2000, vol. 56, pp. 771-82.
151. C. Guerre, P. Laghoutaris, J. Chêne, L. Marchetti, R. Molins, C. Duhamel, and M. Sennour: in 15th International Conference on Environmental Degradation of Materials in Nuclear Power Systems-Water Reactors 2011, 2011, vol. 2, pp. 1397-408.

152. K. Kruska, S. Lozano-Perez, D.W. Saxey, T. Terachi, T. Yamada, and G.D.W. Smith: in 15th International Conference on Environmental Degradation of Materials in Nuclear Power Systems-Water Reactors 2011, 2011, vol. 2, pp. 891-98.

153. K. Kruska: D.Phil. Thesis, University of Oxford, 2012, vol. 1, p. 135.

154. K. Arioka, T. Yamada, T. Miyamoto, and T. Terachi: Corrosion, 2011, vol. 67, p. 035006-1.

155. K. Arioka, T. Yamada, T. Terachi, and T. Miyamoto: in Canadian Nuclear Society - 13th International Conference on Environmental Degradation of Materials in Nuclear Power Systems 2007, 2008, vol. 1, pp. 1-13. 